Año LII urtea

N. ${ }^{\circ}$ 94. zk.

2020

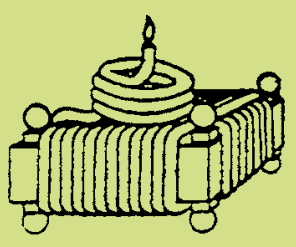

\section{CUADERNOS de Etnología y Etnografía de Navarra}

SEPARATA

\section{Recardera, oficio de mujer}

Ricardo GURBINDo GIL 


\section{Sumario / Aurkibidea}

\section{Cuadernos de Etnología y Etnografía de Navarra}

Año LII urtea - N. ${ }^{\circ}$ 94. zk. - 2020

\section{ARTÍCULOS/ARTIKULUAK}

Etxe izen zizelkatuak. Ageriko idazkunak etxeetan eta hilobietan

Koldo Colomo Castro

Recardera, oficio de mujer

Ricardo Gurbindo Gil

Aralar mugarriturik (1523-1857)

Jose Luis Erdozia Mauleon

El lecayo, una soka-dantza del siglo XVI

Ricardo Urrizola Hualde

El recuerdo público de una muerte política: historiografía periodística y etnografía de la ritualidad pública (José Luis Cano Pérez, 1949-1977)

Kepa Fernández de Larrinoa, Karlos Irujo Asurmendi, Santiago Martínez Magdalena, Txuri Ollo Gorriti, Cristina Saura Blanco

El Camino de Santiago en Navarra en 1971 a la luz de un informe para su mejora elaborado por la Dirección de Turismo, Bibliotecas y Cultura Popular Fernando Vega López

Reformulación del discurso significativo sociocultural en el entramado fortificado de la Línea P (Valle de Roncal-Navarra) 


\section{Sumario / Aurkibidea}

NOTICIAS/BERRIAK

Joxe Ulibarrena y su pasión por la Etnografía

Elur Ulibarrena Herce

Normas para la presentación de originales / Idazlanak aurkezteko arauak / 


\title{
Recardera, oficio de mujer
}

\author{
Errekardari, emakume-ogibidea
}

Recardera, women's job

Ricardo GURBINDO GIL

Licenciado en Historia

r.gurbindo@gmail.com

DOI: https://doi.org/10.35462/CEEN94.2

Recepción del original: 03/06/2020. Aceptación provisional: 03/09/2020. Aceptación definitiva: 08/09/2020. 


\section{RESUMEN}

Recardera es el término mediante el cual se conocía en Navarra y algunas provincias limítrofes a las mujeres dedicadas al comercio al por menor de productos alimenticios (principalmente fruta, verduras, huevos y castañas), así como a la realización en localidades del entorno rural de aquellos encargos y recados encomendados por sus convecinas. Tras una pequeña introducción sobre la presencia femenina en el ámbito laboral, el presente artículo analiza distintos aspectos relacionados con este peculiar oficio, como son el origen del vocablo y su extensión geográfico-temporal; las normativas establecidas por parte de la administración para regular la actividad; las características comunes de estas trabajadoras y la influencia que dicha ocupación tuvo en la vida pamplonesa del pasado.

Palabras clave: mujer; oficio; comercio; productos alimenticios; servicios personales.

\section{LABURPENA}

Nafarroan eta zenbait probintzia mugakidetan, errekardari hitzaren bitartez ezagutzen ziren elikagaien (batik bat, fruta, barazkiak, arrautzak eta gaztainak) txikizkako salerosketan, bai eta landa-inguruneko herrietan bertako biztanleek agindutako enkargu eta mandatuak egiten aritutako emakumeak. Horiek lan-arloan duten presentziari buruzko sarrera txiki bat egin ondoren, artikulu honek ofizio berezi horrekin lotutako hainbat alderdi aztertzen ditu, hala nola hitzaren jatorria eta bere garai eta geografia-hedapena; jarduera erregulatzeko administrazioak ezarritako araudiak; emakume langile horien ezaugarri komunak eta zeregin horrek iraganean Iruñeko bizimoduan izandako eragina.

Gako hitzak: emakumea; ogibidea; merkataritza; elikagaiak; zerbitzu pertsonalak.

\section{ABSTRACT}

Recardera is the term used in Navarre and some neighbouring provinces to refer to women engaged in the retail trade of food products (mainly fruit, vegetables, eggs and chestnuts), as well as in carrying out orders and errands in rural areas commissioned by their neighbours. After a brief introduction on the presence of women in the labour field, this article analyses different aspects related to this peculiar trade, such as the origin of the word and its geographical and temporal extension; the regulations established by the administration to regulate the activity; the common characteristics of these workers and the influence that this occupation had on life in Pamplona in the past.

Keywords: woman; trade; commerce; foodstuffs; personal services. 
1. INTRODUCCIÓN. 2. MUJER Y TRABAJO EN EL MUNDO TRAdiCIONAL. 3. RECARdera: SIGNIFICADO Y EXTENSIÓN DEL TÉRMINO. 4. PARTICULARIDADES DE LA OCUPACIÓN. 5. REgUlaCión de la ACTIVIDAd. 6. PERFIL SOCIOlÓGICO. 7. RECARdERAS PAMPlONESAS. 8. REFLEXIÓN FINAL. 9. ANEXOS. 9.1. Registros de recarderas. 9.2. Normativa reguladora. 9.3. Causas judiciales. 10. REFERENCIAS. 10.1. Bibliografía. 10.2. Hemeroteca. 10.3. Archivos y centros de documentación.

Recardera fue mi madre, y recardera soy yo; habrá buenas recarderas, ¡como la Ricarda no!

La burra recardera, pide cebada; y su dueña le dice, que vale cara.

Pablo Rodríguez González (1900-1977)

«La recardera», Brochazos de la tierrica (cuadros de costumbres, tradiciones, narraciones, $\mathfrak{*}$ ) (1933).

\section{INTRODUCCIÓN}

El número de actividades y ocupaciones surgidas en torno al comercio de los más diversos productos son múltiples y heterogéneas, pero no hay duda de que el papel jugado por los mercaderes e intermediarios resulta clave para que la transacción de bienes pueda llevarse a efecto con éxito. La función de los agentes comerciales detenta tal importancia a este respecto, que su presencia está constatada incluso antes de que se produjera la creación de la moneda como unidad de cuenta. Evidentemente, en este sector existen diferentes niveles de categorías profesionales con base en la dimensión y alcance de los negocios practicados. En nuestro caso, el objeto de estudio del presente artículo se va a centrar en el escalafón último y más básico de esta cadena, el cual ha 
estado representado a través de los tiempos por las vendedoras y revendedoras de a pie de calle, bien sea en su vertiente permanente o itinerante.

El uso que acabamos de hacer del género femenino no es casual, pues, como tendremos oportunidad de comprobar, la presencia mayoritaria de las mujeres en este contexto ha sido una constante desde periodos muy lejanos. Precisamente, el arraigo de esta dedicación en nuestro entorno regional dio lugar a una denominación propia para referirse a quienes se empleaban en esta clase de tareas. De esta manera, cuando, en las páginas siguientes, nos refiramos a las particularidades y circunstancias que atañen a las vendedoras presentes en las plazas en las cuales tenían lugar mercados estables o ferias periódicas, lo haremos mediante el término recardera, pues es así como se conocía a estas trabajadoras en Navarra y otros territorios limítrofes. Evidentemente, también hubo hombres que se dedicaron a este cometido, pero los datos recabados nos indican que lo hicieron en una proporción mucho más reducida.

Son varias las cuestiones referentes a las recarderas en las que vamos a reparar. En primer lugar, se considerará la extensión y significación de la expresión, así como sus relaciones y equivalencias con otras locuciones que sirven para referirse al mismo o similares cometidos. Seguidamente, observaremos en qué medida las autoridades locales regulaban todo lo concerniente a esta modalidad de comercio a través de sus ordenanzas municipales u otros preceptos legales. En otro apartado nos ocupamos de entresacar las características comunes que habitualmente compartían las recarderas, las cuales acabaron otorgando una personalidad e identidad propia a este colectivo de trabajadoras. Por otro lado, gran parte de este trabajo se ha basado en los datos relativos a las recarderas pamplonesas, por lo que nos ha parecido adecuado dedicar un capítulo exclusivo a este grupo concreto de vendedoras.

A pesar de la antigüedad y dinamismo desplegado alrededor de las actividades comerciales vinculadas con el suministro y abastecimiento de los productos básicos de la población, resulta llamativa la poca atención que ha suscitado el fenómeno de las recarderas como protagonistas principales de la venta practicada en el espacio público. No es oportuno adelantar conclusiones desde ya en ese sentido, pero el hecho de que este sea un ámbito laboral en el cual predomina ampliamente el componente femenino puede estar en parte relacionado con esta omisión, pues es conocido que las competencias atribuidas a la mujer en el mundo tradicional normalmente suelen limitar su influencia al medio doméstico. Aunque no se puede negar totalmente tal afirmación, es preciso reconocer que la misma puede admitir ciertas matizaciones.

A menudo, la gestión de la explotación familiar implicaba el cometido de determinadas tareas que sobrepasaban la introvertida esfera del hogar y colocaban a su gestora en comunicación directa con el exterior. El caso de las recarderas es uno de estos ejemplos en los que la mujer superaba el marco privativo de la familia. No obstante, antes de pasar a considerar las peculiaridades de este remoto oficio, consideramos conveniente tener en cuenta algunos aspectos concernientes al estatus femenino en relación con el sistema socioeconómico del pasado. Así pues, a continuación, se van a apuntar algunas ideas elementales que pueden ser útiles para situarnos en 
el ambiente en el cual desarrollaban su misión tanto las recarderas establecidas en las plazas como aquellas otras que ambulaban con sus mercaderías por diferentes lugares.

\section{MUJER Y TRABAJO EN EL MUNDO TRADICIONAL}

La práctica totalidad de monografías sobre las costumbres y modos de vida establecidos en las sociedades del pasado coinciden en resaltar la división de tareas por sexos existente en las ocupaciones laborales. Este reparto conllevaba que el sector femenino quedara relegado a desempeñar las actividades del ámbito doméstico y su entorno más próximo, como el cuidado de la cuadra menor y de la huerta cercana a la casa familiar. El hombre, por su parte, se ocupaba de la ganadería mayor y de las actividades que sobrepasaban el área cercana al hogar. Si bien esta era la pauta ordinaria, también existían determinadas ocasiones en las que hombres y mujeres participaban juntos en una misma faena. Es lo que sucedía cuando las necesidades impuestas por el calendario de labores del medio agrario requerían de numerosa mano de obra, lo que llevaba a la implicación de toda la comunidad sin exclusiones de género (Barandiaran \& Manterola, 1998, pp. 373, 440).

La distribución de trabajos y tareas con base en la condición sexual no era algo que se produjera exclusivamente en este terreno, sino que se extendía asimismo al campo de las relaciones sociales. La población femenina adulta establecía sus vínculos principalmente al amparo de la Iglesia, juntándose a la salida de la misa o participando en asociaciones de carácter religioso. A los hombres, por su parte, les correspondía el espacio de la taberna y la representación en las juntas concejiles, facultad esta que a su vez les confería la responsabilidad de ocuparse de las cuestiones colectivas (Barandiaran \& Manterola, 2011, p. 811).

Este predominio masculino en el plano social estaba compensado en parte por las competencias espirituales atribuidas a la mujer en el marco hogareño, algo realmente esencial si se tiene en cuenta el peso de la religión en los designios morales de la sociedad tradicional. La responsabilidad femenina de disponer y supervisar todo lo relativo al culto familiar era de una enorme transcendencia, y estaba en relación directa con el mayor o menor prestigio del propio clan frente a la comunidad. Entre las tareas comprendidas en este compromiso estaban las del cuidado de la sepultura de los antepasados, la formación religiosa de las nuevas generaciones o la bendición de la casa y demás elementos fundamentales de la vida diaria (Manterola, 1980, p. 596). Sin duda, la asignación de este cometido evidenciaba la autoridad femenina en esta parcela, pero no dejaba de ser una función limitada al hábitat particular.

Precisamente, este dominio de la mujer en la organización de la vida familiar ha llevado frecuentemente a plantear su liderazgo en los asuntos claves que encauzaban la subsistencia diaria de la comunidad. Evidentemente, el ejercicio de este compromiso en el papel de madre y esposa colocaba a la mujer en una situación decisoria respecto al mantenimiento y continuidad del linaje y, por consiguiente, con efectos en el ente común surgido de la fusión de todas esas unidades familiares. Sin embargo, está por valorar del todo el 
verdadero alcance de esta atribución, e incluso hay quien considera como ilusoria esta supuesta preponderancia femenina cuando en la práctica era el hombre quien efectivamente detentaba el poder de decisión en el contexto público y social (Valle, 1996, pp. 39, 63).

Al margen de cuál de estas dos visiones es la más acertada, lo cierto es que ha existido una división notoria en la adjudicación a cada sexo de los espacios público y privado, resultando el género femenino el más perjudicado debido a la invisibilidad que implicaba tal distribución. Dicha organización antropocéntrica de la sociedad ha provocado que los cometidos desempeñados por la mujer en gran medida hayan pasado desapercibidos, pues la narración del desarrollo humano se ha realizado con base en las decisiones y actos impulsados por los poderes político, económico, cultural o religioso a los que esta no tenía acceso. La aportación de las mujeres al progreso social es indudable, pero la circunstancia de que esta haya partido desde la privacidad ha suscitado su inadvertencia.

Desde luego, tal situación no ha sido casual, sino que responde a unos condicionantes establecidos previamente. Históricamente, el moralismo ha impuesto la propagación del modelo doméstico femenino, al cual, de paso, le ha asignado un firme sentido devoto. Fray Luis de Léon sintetizó a la perfección el fundamento de este ideario cuando expuso que las labores del hogar eran la mejor forma de llegar a una vida de santidad. El planteamiento propuesto por el religioso agustino defendía que la mujer debe «trabajar sin parecer que lo hace», lo cual es indicativo de la escasa relevancia social concedida a la misma (Garrido, Folguera, Ortega \& Segura, 1997, p. 329).

La mayoría de estas tareas ejercidas por la mujer en el entorno restringido del hogar tenían como objeto principal la satisfacción directa de necesidades personales de otros seres. Estos servicios particulares resolvían todas las exigencias corporales y materiales que la vida diaria imponía a la unidad familiar, y muy pocas veces eran retribuidos con una compensación económica.

En cualquier caso, algunos de estos cometidos necesariamente conllevaban también un contacto con el exterior, lo que en parte servía para romper con el aislamiento impuesto. La participación femenina en determinadas operaciones

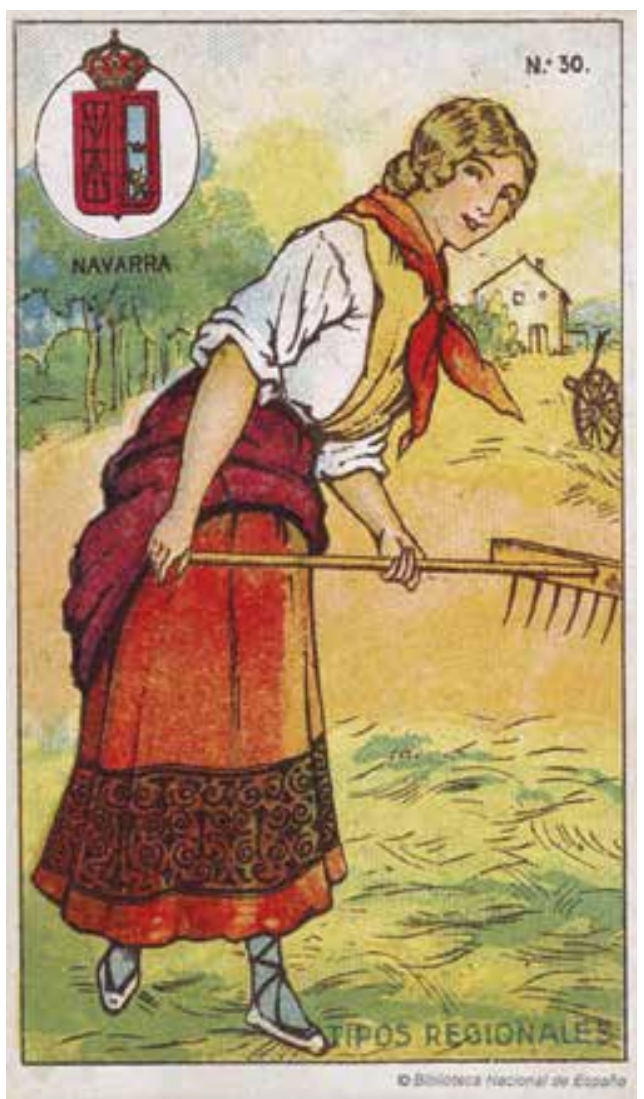

Figura 1. Mujer navarra realizando labores agrícolas. Colección de cromos de tipos regionales, n. ${ }^{\circ} 30$ - Navarra. Biblioteca Digital Hispánica (BNE). 
del ciclo agrícola, como la escarda o la recolección, era algo habitual, y tampoco era excepcional encontrar a mujeres ejerciendo el pastoreo. Con todo, estas actividades no conferían el mismo grado de autonomía que la práctica de algunos oficios artesanales como ocurría con las tejedoras, esparteras, candeleras, etc. (González, 1985, pp. 18, 41).

Otra actividad enmarcada en el sector terciario desempeñada asimismo por la mujer estaba relacionada con el aprovisionamiento diario de alimentos y otros suministros de primera necesidad. El predominio femenino no se daba solo en lo que a la adquisición de estos productos se refiere, sino que mayormente las responsables de la venta también eran mujeres. En unos casos se trataba de negocios fijos establecidos conforme a la pertinente licencia municipal, pero en otros la dedicación era más esporádica. Las mujeres que se empleaban en este comercio al por menor lo hacían condicionadas por su situación familiar. Aunque en principio cualquier otra actividad que no fuera el cuidado de la familia no estaba bien vista, la mayor vulnerabilidad económica a la que se veían expuestos los hogares con un solo varón, así como aquellos en los que el cabeza de familia había fallecido, disculpaba esta inserción de la mujer en el mundo laboral (Anaut, 2005, p. 35).

Desde el Medievo, el ámbito del mercado ha constituido un marco ideal donde obtener unos ingresos fundamentales procedentes del ramo de la alimentación, pues ofrecía diversas alternativas para ello (Campo, 2005, p. 29). El comercio más especializado lo protagonizaban quienes de manera habitual despachaban mercancías adquiridas previamente a proveedores y mayoristas más o menos oficiales. En un segundo nivel se encontrarían aquellas vendedoras que aprovechaban el espacio público de la plaza para dar salida al excedente de la propia producción familiar. Por último, el rango más bajo de esta escala estaba integrado por revendedoras que, tras hacerse con algunas provisiones por encargo o iniciativa propia, intentaban luego colocar cargándoles una pequeña comisión.

\section{RECARDERA: SIGNIFICADO Y EXTENSIÓN DEL TÉRMINO}

Las mujeres dedicadas a estos quehaceres en nuestro entorno eran conocidas como recarderas. La aceptación y utilización del vocablo para referirse a estas trabajadoras era general, de hecho, así aparecen nombradas en los documentos producidos por las instituciones locales que regulaban esta actividad. El entorno de la casa consistorial de Pamplona era uno de los lugares donde se concentraba un número considerable de recarderas, por lo que no es extraño que el archivo de la ciudad custodie abundantes expedientes relacionados con la actividad desarrollada en este sector. Más adelante, en un apartado propio, nos ocuparemos de las particularidades de las recarderas pamplonesas, pero en este punto nos parece oportuno recuperar la definición añadida en su día a la cubierta de los legajos que conservan la extensa documentación relacionada con esta ocupación. La aclaración contenida en dicho encabezamiento es la siguiente:

Se llamaba así a las que tenían un puesto de venta o banco de recardería, con autorización del Ayuntamiento, en la plaza de Arriba o de la Fruta, hoy plaza del Ayuntamiento, o en la plaza de Abajo (entre la Casa Consistorial y la iglesia de Santo Domingo) o en 
alguna calle u otro punto de la ciudad. Se les concedía el uso de peso en su tienda, venta de huevos frescos y fruta seca. También fruta verde y castañas por peso y por maravedís. Igualmente, velas de sebo de la Provincia por velas sueltas, mas no por libras ${ }^{1}$.

Con objeto de completar esta explicación, consultamos el Vocabulario navarro de José María Iribarren (1997, p. 434), recurso imprescindible a la hora de reparar en expresiones propias del léxico local. Según explica la voz correspondiente, el término 'recardera' aludía a las vendedoras y revendedoras de verduras y hortalizas de la Cuenca de Pamplona. Igualmente, el diccionario incluye bajo esta misma denominación a las recaderas en general (personas que tienen por oficio llevar recados de un punto a otro) y a las recoveras (mujeres dedicadas a la recova o compra de huevos y otras cosas para revenderlos). Otras entradas incluidas en esta obra y que completan el glosario de esta ocupación hacen referencia a las formas 'recardear', como sinónimo de revender, y 'recardiado', locución que alude a la mercancia obtenida tras su reventa.

Una de las fuentes en las que Iribarren basa parte de su exposición sobre las recarderas es el relato que sobre ellas hizo Pablo Rodríguez González (1933, pp. 191-196). El escritor y religioso de Arellano dejó testimonio de muchas de las costumbres y ocupaciones comunes de comienzos del siglo pasado en su libro Brochazos de la tierrica. Respecto a las recarderas, les atribuye la doble función de ejecutar los encargos confíados por sus convecinos y la de revender las chucherías y baratijas con las que se hacían en el mercado semanal de Estella. Los tipos de recados que se les encomendaban a estas mujeres comprendían desde la reparación de pequeños artilugios, hasta la adquisición de los productos habituales del ferial u otros más especiales procedentes de establecimientos específicos como las boticas. Solía ser habitual que el solicitante de los servicios de la recardera abonara con antelación el coste que implicaba su demanda.

La figura de estas personas dedicadas a la ejecución de los más variados encargos la encontramos en numerosas localidades. Las recarderas de Lumbier se valían del ferrocarril El Irati para trasladarse a los comercios de Pamplona y adquirir aquellos productos que les solicitaban. Para otro tipo de encargos, como los relacionados con la costura, optaban por un trayecto menor y se desplazaban hasta Sangüesa. La última recardera que recuerdan en Lumbier era Julia la Solanillesa, quien no solo se ocupaba de llevar al pueblo los artículos solicitados, sino que también aprovechaba la ida de sus viajes para extraer productos locales, como huevos y verdura, que luego revendía en su destino (Ibáñez, 2007, pp. 270, 317).

En la Ribera también operaban esta especie de «enviados». Luis María Marín (2007, p. 443), en su diccionario del habla ribera, alude a la recua de carros de los recaderos que a diario llegaban hasta Tudela de los pueblos de los alrededores para adquirir «una lista interminable de cosas que les habían encargado en sus lugares de origen». Igualmente, 
los tudelanos salían fuera de su ciudad en busca de productos procedentes del exterior, y enviaban recaderos a Pamplona y Zaragoza, «hombres y mujeres que se dedicaban a hacer recaos y comprar encargos a la gente». Estas personas recibían sus enconmiendas siempre en una misma taberna y realizaban los viajes determinados días de la semana. Una variante de este singular oficio en el área ribera eran las geroveras, expresión posiblemente relacionada con el término 'recovera', mujer empleada en la recova o compra de huevos y otros productos para su reventa. Las evocadas por el investigador tudelano se trasladaban en autobuses de línea y, como en otros lugares, aprovechaban el viaje para llevar huevos, aceite y frutas que vendían en las tiendas o a clientes habituales. A la vuelta traían los objetos que les habían solicitado en su pueblo, por lo general, ropa interior $\mathrm{u}$ otras prendas poco comunes no asequibles en pequeñas poblaciones.

En el fondo, aunque hallemos denominaciones diferentes, el cometido desempeñado por estas personas era muy similar en unos y otros lugares. Por otro lado, el habla popular no es algo inalterable, sino que evoluciona con el paso del tiempo. Marín recoge las expresiones recadera y recáu por ser estas las que estaban vivas en la mente de los vecinos de la merindad de Tudela cuando él realiza su vocabulario. Sin embargo, el término recardera no ha sido desconocido en la zona, y es precisamente en Tudela donde hemos encontrado la noticia más antigua en la que esta palabra es mencionada. En concreto, se trata de una referencia hecha en el medieval Libro de Recibidores de Ayuda, conocido como «cuentas del veinteno» por ser este el gravamen aplicado por Carlos II de Evreux a las compras y ventas efectuadas por los navarros. En el registro de la actividad comercial desarrollada en el mercado tudelano correspondiente al año 1363, se constata que la presencia de productos hortofrutícolas era muy variada, siendo como poco «tres mujeres recarderas o vendedoras de fruta y verdura» las que regularmente instalaban su puesto de venta: «María Blasco, la Gocha y la Pechera» (Mugueta, 2017, p. 152).

Así pues, al menos desde la Edad Media y hasta las décadas centrales del pasado siglo encontramos alusiones a las recarderas como tal en distintos puntos de Navarra. Por ejemplo, a raíz de la nevada caída en Pamplona nada más comenzar 1945 se produjó tal subida en el precio de las frutas y hortalizas que llegó a ser objeto de noticia en las páginas de los periódicos. De los distintos comentarios publicados recuperamos uno que criticaba el elevadísimo coste de la verdura, y señalaba como anécdota que «de nuestra vega rochapeana subieron algunas cestas y pudimos escuchar a una recardera pedir cinco pesetas por un cardo, y cuatro por una berza $»^{2}$.

Respecto a la etimología del término 'recardera', este procedería de la nominalización de la accion verbal de 'recardear', formas ambas del habla popular local equivalentes a 'recadera' y el acto propio de ejecutar tales recados. Por su parte, el origen de la palabra 'recado' se encuentra en el verbo 'recadar', que significa recoger o recaudar, expresiones que surgen del latín clásico 'recaptare' (derivado de 'accaptare', comprar o coger). Según el diccionario etimológico de Joan Corominas (1987, p. 496), la forma romance más 
antigua conocida es 'recabdar' (hacia 1140), de la cual nació la reducción castellana 'recadar', germen a su vez de 'recado'. Así pues, todo parece indicar que las expresiones 'recardera', 'recardear' y 'recardar' no serían sino diferentes locuciones locales del modo romance de 'recabdar', formadas por un proceso fonético similar al seguido por la derivación castellana vigente de 'recadar', específicamente, recoger recados (Hernández, 2001, p. 1147).

Del mismo modo, la extensión de la expresión recardera a todo el territorio navarro conllevó la lógica traslación del término al léxico de lengua vasca. El estudioso del euskera y de las lenguas orientales Eusebio Elzaurdia Zubieta (1874-1956), más conocido como fray Eusebio de Etxalar, incluía el vocablo 'arrekardari' en una investigación realizada sobre las voces vascas en los fueros de Navarra (Elzaurdia, 1921, p. 30). A diferencia de lo ocurrido en castellano, la forma vasca 'errekardari' sigue presente en el vocabulario actual homologado por Euskaltzaindia, siendo varias las menciones a dicha voz existentes en la base de datos histórica y literaria de esta institución ${ }^{3}$. De esta manera, la existencia y permanencia de las referencias a esta dedicación en los dos idiomas de Navarra no hacen sino constatar la actuación de las recarderas en las diferentes zonas y pueblos de la comunidad.

Por otro lado, también es preciso puntualizar que, a menudo, las relaciones sociales y culturales entre comunidades no suelen reparar en los límites territoriales oficiales, por lo que no es raro encontrar muestras de una misma manifestación o hecho en comunidades vecinas. En consecuencia, no debe sorprendernos la presencia de la misma denominación para referirse a las mujeres dedicadas a este tipo de comercio en Gipuzkoa, así como en las provincias de Huesca y Zaragoza de la Comunidad Autonoma de Aragón.

Después de Navarra, es en el territorio guipuzcoano donde mayor número de alusiones directas a las recarderas hemos encontrado. En los mercados donostiarras de la Brecha y San Martín era habitual la presencia de puestos regentados por recarderas que revendían huevos, verduras y hortalizas previamente adquiridas en los caseríos o a las caseras que bajaban a la ciudad. También ofrecían su productos a comercios y restaurantes, pero en estos casos el margen de ganancia solía ser inferior. Cada día las caseras se desplazaban hasta la capital portando sobre sus cabezas, en burro o en carro, los productos de la huerta, la leche, los huevos... En unos casos ofrecían su producción a las revendedoras, pero otras veces la despachaban personalmente ellas mismas en el mercado. Para ello era preciso salir del caserío antes del amanecer, ya que antaño no se reservaban los puestos como ocurre hoy, y solo las primeras en llegar tenían opción de exponer su mercancía sobre una tabla a modo de tenderete (Campos \& Rodríguez, 2000, pp. 452, 454). Aunque en menor medida y más alejadas en el tiempo, en las igualmente colindantes provincias de Huesca y Zaragoza también hay

3 Euskaltzaindia. Orotariko euskal hiztegia, literatura terminoen hiztegia eta argitalpen historikoak. https:// www.euskaltzaindia.eus/index.php?option=com_bilatzaileaweb\&task=indizeaKontsultatu\&view=emaitzaa zaldu\&query=errekardari 
constancia del uso de la palabra recardera en este mismo contexto mercantil. Concretamente, nos referimos a varias ordenanzas dictadas en la Edad Media, de las cuales nos ocuparemos más adelante en el apartado correspondiente a la regulación de la actividad.

Con todo, a fin de cuentas, no estamos hablando más que de la forma específica utilizada en un determinado entorno para aludir a un oficio que puede considerarse universal. De hecho, la realización de encargos a nivel particular y el pequeño negocio de productos adquiridos para su reventa es una actividad repetida indistintamente en prácticamente todos los lugares. Por ejemplo, en Extremadura las personas dedicadas a cumplir las encomiendas de sus convecinos recibían el nombre de jateros (Pedrosa, 2000 , p. 850), pero, salvando la diferente designación y las peculiaridades regionales, se trataba de una ocupación con más similitudes que diferencias.

Más conocidos y generalizados han sido los términos regatera y regatona para referirse a las mujeres ocupadas antiguamente en el comercio al por menor desarrollado en ferias y mercados (Rucquoi, 1985, p. 11). Aunque estas revendedoras no llegaban a conformar gremios o corporaciones estables y formales, tampoco se descuidaban cuando se trataba de defender los derechos adquiridos por la fuerza de la costumbre. Es el caso de las regatonas vitorianas, las cuales en 1780 se organizaron en grupo para manifestar su malestar por la nue-

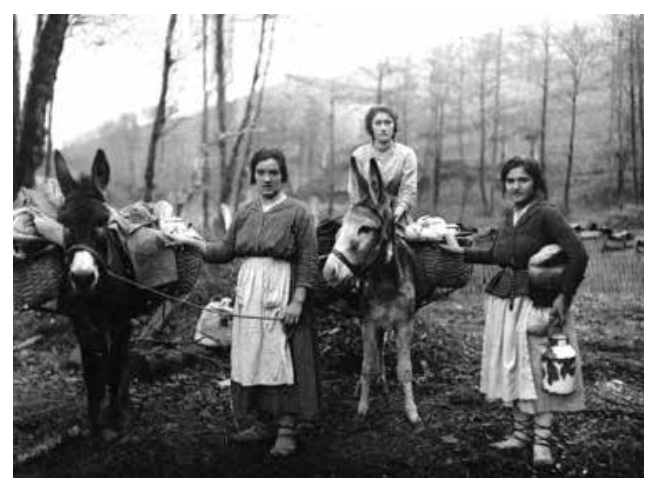

Figura 2. Caseras guipuzcoanas camino del mercado. Fotografía: Indalecio Ojanguren (guregipuzkoa. eus). va distribución espacial del mercado dispuesta por las autoridades. Curiosamente, una de las portavoces designadas para interlocutar con los mandatarios municipales era conocida con el significativo sobrenombre de María de Regardera (Roquero, 2019, p. 358).

\section{PARTICULARIDADES DE LA OCUPACIÓN}

Las noticias expuestas sobre la expansión física y cronólogica del fenómeno de las recarderas constatan su presencia en diferentes épocas y localidades. A continuación, vamos a mencionar algunos ejemplos ilustrativos de la heterogeneidad de cometidos desempeñados y el tipo de solicitante tan diverso que demandaba sus servicios. Los pedidos realizados a las recarderas no solo procedían de las clases humildes, sino de todos aquellos que tuvieran necesidad de los productos con las que estas mercadeaban. Así pues, no resulta extraño que las cuentas del banquete celebrado en 1442 por el veintiún cumpleaños del Príncipe de Viana consignaran los cuarenta sueldos abonados a "Gintia, recardera, por los cinco carapitos de leche por fazer coallada et natas» (Serrano, 1998, p. 709). 
Un problema al que las recarderas debían enfrentarse en ocasiones era el impago de los productos despachados, y la reclamación de las cantidades adeudadas dio origen a numerosos procesos judiciales. Dado que la clientela de las recarderas abarcaba todo el espectro de clases sociales, no debería sorprendernos que algunas de las denuncias afectaran incluso a personalidades respetables. Una situación de este tipo es la que sobrevino tras la muerte de Juan de León, despensero de la casa del obispo Diego Ramírez Sedeño de Fuenleal (1524-1573). La demandante era Juana de Usi, recardera que durante diez años había surtido de:

pescado, cereal, aceyte y todas las otras cosas que tenía en una botiga, para la despensa de la cassa del dicho obispo, y algunas aves; y también le prestaba dinero para comprar pescado fresco y velas de sebo y cera, y otras cosas; y al cabo de algunos días se mataban quentas y le pagaba lo que le alcanzaba.

Antes de fallecer, el propio despensero, teniendo como testigos a los mayordomos y veedores del obispado, dejó constancia por escrito del montante que se adeudaba a la recardera, pero, posteriormente, esta no recibió ningún dinero por los alimentos suministrados hasta entonces. El caso es que la denuncia presentada por Juana de Usi ponía en un verdadero compromiso al Consejo Real de Navarra, el cual no vio otra solución que enviar una misiva a Diego Ramírez para que «parezcáis en nuestro dicho Consejo por vosotros mesmos o por vuestro bastante procurador a tomar la dicha petición, y dar causas por qué no se debe pagar la cantidad que el suplicante por la dicha petición inserta y pide, y estar a justicia con él sobre ella».

En cualquier relación comercial surgen contrariedades económicas como la expuesta, pero no es algo que afecte en exclusiva al proveedor. Tampoco las recarderas estaban siempre al día en el pago de sus obligaciones, por lo que también ellas hubieron de hacer frente a demandas por cuestiones de este tipo. Lógicamente, si no querían tener problemas de esta índole, el género con el que comerciaban debía ser abonado a los productores o a los mayoristas que se lo facilitaban. Así mismo, según fuera la magnitud de la actividad comercial desempeñada, había una serie de tributos y arbitrios que la recardera debía satisfacer. El incumplimiento de uno y otro deber dio lugar a abundantes causas motivadas por faltar a estos compromisos en la reventa de productos alimenticios. De esta manera, la recardera María de Ciáurriz se vio envuelta en un pleito a raíz de la denuncia impuesta por el arrendador de una pescamercería al no haber recibido este el pago del producto servido ${ }^{5}$. Por su parte, Antón de Larráinzar, arrendador de la alcabala pamplonesa, se querelló contra María de San Martín, viuda del recardero Martín de Ciáurriz, por las cantidades debidas y no abonadas por su marido ${ }^{6}$.

4 ARGN, Consejo Real de Navarra, Procesos judiciales, F017/068888.

5 ARgn, Corte Mayor de Navarra, Procesos judiciales, F146/164155.

6 ARGN, Consejo Real de Navarra, Procesos judiciales, F017/010880. 
Pero la figura de las recarderas no estaba definida solo por la venta y reventa de deteminados productos, principalmente alimentos, en los núcleos de una cierta significación. En un contexto más rural y menos accesible a los bienes de consumo en general, las atribuciones de este personaje se incrementaban de tal manera que las recarderas podían ser requeridas para cualquier tipo de encargo. Las encomiendas abarcaban toda clase de recados relacionados con la adquisición de los más diversos artículos e incluso su reparación. Dentro de esta pluralidad de misiones había algunas que eran realmente peculiares. La petición recibida por el recardero de Allo constituye una anécdota curiosa que de nuevo nos llega a través de una narración incluida en el libro de Pablo Rodríguez, la cual también vio la luz en la revista La Avalancha ${ }^{7}$. En el relato, titulado «El cerdo de la rifa», se describe jocosamente la adquisición, en la feria de Estella, y el traslado a Allo del cochinillo que se cuidaba y engordaba para el sorteo celebrado en las fiestas a beneficio de la cofradía de la Vera Cruz. De esta manera, el célebre «cerdo del Santo Cristo» fue transportado en la «sección correspondiente» del carro del recardero local.

En el ámbito meramente comercial, la acaparación de ciertos productos, como los huevos, por parte de las recarderas, provocaba una escasez de género que posibilitaba a estas jugar con el precio y aumentar así su beneficio. El mercado de Irurtzun era una de las plazas fuertes de estas revendedoras. Gracias a un emplazamiento donde confluyen varias vías de comunicación en diferentes direcciones, las ferias celebradas los días 10, 20 y 30 de cada mes contaban con «asistencia numerosísima de ganaderos y ganado, comerciantes y mercancías, carruajes, etc., ferias que habían otorgado al lugar una supremacía indiscutible en el valle y lo convertía en uno de los más visitados» (Altadill, 1918-1921, p. 37).

En esta plaza, el acaparamiento de los huevos por parte de las recarderas llegó a constituir un verdadero problema para las autoridades, pues la ganancia que obtenían estas mujeres procedía de la elevada comisión que posteriormente cargaban al producto. El informe sobre los productos disponibles y su coste en el primer ferial de diciembre de 1915 afirmaba que «el comercio de huevos, pollos y gallinas no da ni para remedios y enseguida se hacen las recarderas con ellas». Lejos de solucionarse, el problema para abastecerse de estos alimentos provocado por la especulación fue a más, por lo que, unos años más tarde, el gobernador civil dio órdenes al teniente de la Guardia Civil del puesto de Irurtzun para que procediera a incautar las «incalculables existencias de huevos comprados por las recarderas $»^{8}$.

\section{REGULACIÓN DE LA ACTIVIDAD}

Sin duda, el despacho de las mercancías alimenticias producidas en el cinturón agropecuario circundante a la ciudad tradicional y de los excedentes llegados desde el exterior, así como de esos otros productos que acababan en las cabeceras de comarca rurales, no

7 La Avalancha, n. ${ }^{\circ} 1068,24 / 10 / 1939$.

8 Diario de Navarra, 03/12/1915 y 02/03/1921. 
tenía exclusivamente una repercusión específica y estanca, sino que su impacto transcendía a diferentes contextos. Por ejemplo, el comercio también suponía uno de los grandes sustentos de la economía de las instituciones locales, pues muchos de sus ingresos procedían del arrendamiento de las licencias y derechos de venta, además de los aranceles con los que se gravaban las mercancías. De la misma manera, este tipo de transacciones generaba una serie de dinámicas transversales que era preciso regular, por lo que las ordenanzas de los diferentes municipios procuraban precisar al detalle el funcionamiento de dichas actividades.

En el caso de Pamplona, un tratado tan relevante como el Privilegio de la Unión (1423) ya hacía referencia a la profesión que nos ocupa. El documento, que instaura el vínculo entre los tres burgos que formaban la urbe de Pamplona en la Edad Media, dedica su capítulo veinticinco a la capacidad de los jurados «para administrar justicia en todo lo relativo a malicias y fraudes que cometieran los menestrales de diferentes oficios de la ciudad, pudiendo imponer correcciones y prender y detener en prisión a los defraudadores» (Olivier, 1928, p. 84). Exactamente, el texto cita a los

argenteros, costureros, tenderos, correctores, recarderos o recarderas, molineros, zapateros et pellejeros et otros qui han otros oficios públicos, et toman las gentes comunes cosas para vender, o fazer de su oficio, et aquellas no pueden cobrar deyllos en los términos concordados (Zuaznávar, 1828, p. 385).

Documentación posterior elaborada por el Ayuntamiento de Pamplona alude igualmente a distintas cuestiones que afectaban directamente a las recarderas. Por ejemplo, en 1764 se promulgaron las ordenanzas reguladoras de la forma de obrar del fielato 9 «en quanto a lo que deben quitar de estima a los arrieros y demás personas que trajeren a vender todo género de abastos a la ciudad». Una de las partes de este edicto pretendía proteger al vecindario «de los perjuicios que hasta aquí le han resultado del manejo, o comercio de frutas, que se hacía entre sus conductores y las recarderas».

Para lograrlo se establecía un horario determinado en el cual proceder a la descarga del producto, quedando prohibido hacerlo fuera de él, salvo «consentimiento y licencia del señor regidor semanero». Con objeto de que la ordenanza fuera cumplida debidamente, el fiel que se hallase de semana tenía la obligación de darla a conocer «desde luego a todas las recarderas, y a los vendedores de frutas, conforme fueran llegando con ellas, para que cada uno en la parte que le toca la obedezca puntualmente, pena de dos ducados, que irremisiblemente se exigirán a cada uno de los que contravinieren».

Unos años más tarde, en 1772, el Consistorio dictó nuevas ordenanzas para la limpieza de la plaza de la Fruta, y determinó que el saneamiento de la misma era «cargo y obligación de las panaderas, fruteras y recarderas, y que en ella estuvieren empleadas,

9 Fielato: oficina a la entrada de las poblaciones que contrastaba pesos y medidas y en la cual se pagaban los derechos de consumo. 
y de las personas que ocuparen las tiendas de su recinto, cada cual respectivamente». Los administradores de las tiendas ubicadas en la plaza tenían el deber de barrer desde el umbral de la puerta de sus negocios hasta la primera línea de piedras taladradas que servían para asegurar los tenderetes de las fruteras, y estas, junto a las recarderas y panaderas, el resto de la superficie (Arazuri, 1979, p. 235). Del mismo modo, sin referirse a ninguna obligación ni quehacer concreto de estas trabajadoras, el conocido como Libro de la Peste, en el cual se narra lo sucedido y las medidas adoptadas por la administración local cuando en 1599 la enfermedad asoló la ciudad, también menciona a las recarderas pamplonesas, pues, como tantas otras pamplonesas, varias de ellas sufrieron las duras consecuencias de la epidemia (Baleztena, 1946, pp. 382 y 387).

Pero el escrito que en mayor medida nos informa sobre los deberes y condiciones impuestas a este colectivo de mujeres por la administración local son las «Hordenanzas de la plaça y chapitel de los recarderos y fruteros». El mandato municipal regulaba distintos aspectos de la actividad desarrollada por las recarderas, fijando asimismo su número y distribución «en la plaça del chapitel, como fuera de ella, en los calliforques y cantones». Para ejercer el oficio era fundamental haber sido autorizada por el Regimiento, y para aquellas que no cumplieran este trámite se establecía una "pena de quince libras, repartideras la mitad para el acusador y la otra mitad para los ussos desta Ciudad».

El nombramiento requería de un juramento previo de honestidad en el desarrollo de la actividad comercial a realizar, pues a cada recardera se le concedía licencia para vender solo un determinado género. De esta manera, las mujeres que vendían fruta tenían vetado el comercio con pescado o aceite, y lo mismo sucedía a la inversa. Otras cláusulas hacían referencia a los horarios y precios de venta, así como a la importación y exportación de alimentos sin el oportuno permiso de la autoridad. Todas las disposiciones incluían al final el importe económico del castigo al que se exponían quienes contradijeran la normativa.

Este reglamento, incluido en una compilación legislativa realizada por el Consistorio $^{10}$, ha sido datado por los investigadores Santiago Lasaosa (1979, p. 89) y Marcelino Núñez de Cepeda $(1948$, p. 234) en el siglo XVI. Según este último, las recarderas no habrían llegado a formar un gremio como tal, pues era un oficio que dependía en gran medida de la voluntad de los regidores y, en consecuencia, no existiría una estabilidad duradera que posibilitara la organización corporativa de las trabajadoras. Sin embargo, aunque no hubieran establecido una agrupación formal, algunas decisiones tomadas conjuntamente sí que nos advierten de una mínima conciencia de grupo. La organización de su distribución física acordada en común según los distintos productos de venta de cada recardera, o las denuncias cursadas contra aquella compañera que hubiera vendido un género distinto del que había obtenido autorización, son acciones indicativas de una cierta conexión entre ellas ${ }^{11}$.

10 AMP, Libro de las Hordenanzas de la ciudad y de diferentes oficios de esta de Pamplona, ff. 16-20.

11 AMP, Empleados, leg. 16, carp. 1: Recarderas (1815-1838). 
La regulación de la labor de las recarderas también se llevó a cabo en otros lugares de Navarra en los que estas operaban. Una de estas poblaciones era Puente la Reina/Gares, donde uno de los artículos de las Ordenanças de la villa de la Puent de la Reyna regulaba y restringía la compra de géneros del exterior, demostrando una clara política proteccionista favorable a los productores locales. La norma adoptada en el Bajo Medievo establecía que "ostalero alguno o ostalera, mercadero o mercadera, recardero o recardera ni otro vezino alguno de la dicha villa, non pueda comprar en groso provisiones algunas, mercaderías ni averíos que personas estrangeras traygan a vender a la dicha villa» (Segura, 2003, p. 160). Así mismo, el ordenamiento local establecía los parámetros pertinentes respecto a los horarios y precios a seguir en las transacciones a realizar en la localidad.

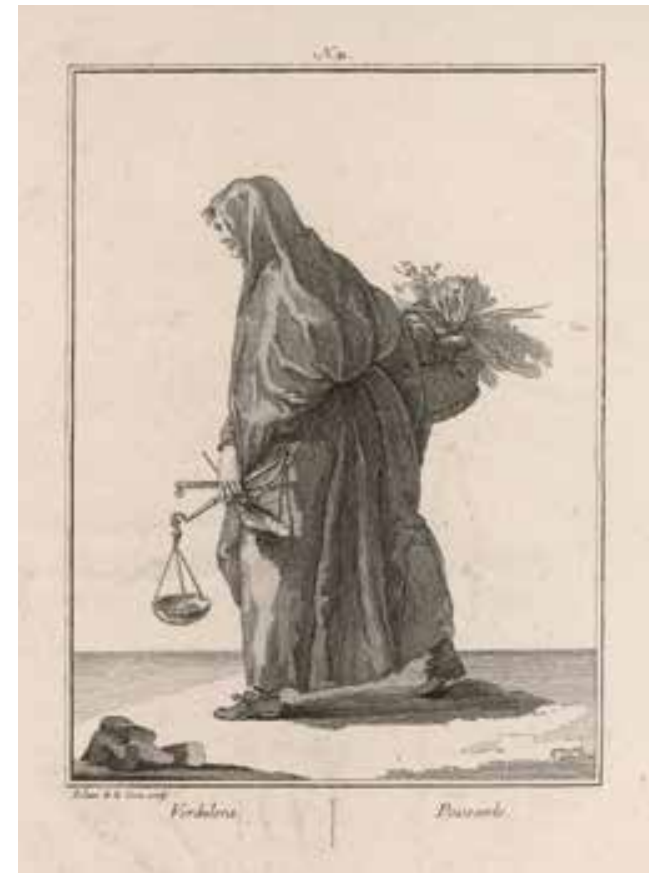

Figura 3. Verdulera / Poissarde. Grabado de Juan de la Cruz, 1777. Biblioteca Digital Hispánica (BNE).

Similares disposiciones adoptaron en Lesaka durante el mismo periodo con objeto de regular el funcionamiento del mercado. Aunque los encargados de transportar las mercancías hasta la villa eran los mulateros, la venta al por menor de los alimentos en su interior la realizaban las recarderas. Las ordenanzas locales, buscando la moderación y estabilidad de los precios, limitaban los beneficios de las revendedoras, quienes tenían prohibido "salir al camino de los mulateros», así como "azer preçio asta venir a la picota, ni ablar sobre preçio asta que aga su tiempo dicha picota como está ordenado». Por otro lado, los datos de la alcabala informan sobre cuáles eran los productos más consumidos en la zona (avena, mijo, sal, aceite...), evidenciando la penuria de la comarca en productos alimenticios elementales (Jiménez de Aberasturi, 1980, p. 329).

Obviamente, el quebrantamiento de estos códigos conllevaba la aplicación de la sanción establecida y las condenas por esta causa se repiten de unas épocas a otras. De esta manera, nos encontramos con situaciones como la experimentada por Graciana de San Martín, recardera y vecina de Pamplona, quien fue detenida y procesada en 1583 por la venta de perdices de forma ilícita ${ }^{12}$. A finales del siglo XVIII, por un motivo similar, fueron castigadas con un ducado de multa las recarderas pamplonesas Bernarda Estrada, 
Luisa Ponze, Luisa Zunzarren, Rosa Martínez y Francisca Moreno ${ }^{13}$. Todas ellas tenían autorización del Regimiento para la venta de carbón y sarmientos, pero también ofertaban cuajada a su clientela sin tener licencia para ello. A pesar del transcurso del tiempo, siguieron produciéndose denuncias similares; es el caso de la cursada por los agentes municipales, en marzo de 1907, contra «una recardera de la plaza por hacer la compra antes de la hora reglamentaria» ${ }^{14}$.

Además de las imputaciones por infracciones a las ordenanzas específicas de su oficio, evidentemente las recarderas también estaban obligadas a actuar según las rígidas y puritanas pautas de comportamiento de la sociedad tradicional. En este sentido, el hecho de desempeñar su labor a diario en el espacio público exponía a estas trabajadoras de una forma constante. Los castigos por no actuar conforme al modelo moral impuesto por las autoridades civiles y religiosas eran incluso superiores a los de otra índole. Por ejemplo, en 1796 doce recarderas fueron desautorizadas para practicar su oficio al ser consideradas «incumplidoras y demasiado libres», y se motivó su expulsión por no conocérseles «otra ocupación que la superficial de sus buhonerías, contra las cuales declama el espíritu de las leyes del Reino" (Garralda, 2011, p. 270). Este tipo de argumento gratuito lo encontramos asimismo a comienzos del pasado siglo, cuando una recardera de Pamplona fue denunciada por escándalo en la plaza del mercado ${ }^{15}$.

Como hemos adelantado antes, en la legislación local de comunidades lindantes con Navarra también encontramos noticias que hacían uso del término recardera para referirse a estas vendedoras callejeras. Las ordenanzas de Huesca de 1349 pretendían asegurar el abastecimiento de su población con unos precios y condiciones no abusivas. Igualmente, regulaban la contribución que las personas dedicadas a estos quehaceres debían abonar por cada transacción en beneficio de la institución municipal (Arco, 1913, p. 432).

Sin dejar la Comunidad de Aragón, sabemos que en Zaragoza utilizaban la misma denominación gracias a un manuscrito titulado El registro del merino de Çaragoça (12911312). Esta recopilación, redactada en el dialecto medieval navarro-aragonés, informaba, en el apartado relativo a los tributos percibidos por la administración del Reino de Aragón, que todo recardero de ganado, tanto bestial como menudo, debía de pagar peaje y lezda (Bofarull, 1889, p. 12). Así mismo, los diccionarios de voces aragonesas elaborados por Mariano Peralta (1836, p. 39) y por Gerónimo Borao (1859, p. 229) en el siglo XIX recogen ambos la palabra recardero como sinónimo de revendedor.

Más recientes que las ordenanzas mencionadas son las decretadas en 1890 por el Ayuntamiento de Donostia para regular la venta de alimentos en la ciudad. El reglamento utiliza el término recardera cuando alude a las mujeres dedicadas a la reventa en

13 AMP, Empleados, leg. 13, carp. 10: Recarderas (1730-1772).

14 El Eco de Navarra, 21/03/1907.

15 Diario de Navarra, 10/11/1920. 
los mercados donostiarras. Como en otros lugares, estas tenían limitado su horario de compra al objeto de evitar la excesiva especulación con los precios. En consecuencia, no podían:

salir de sus puestos a comprar para revender hasta las diez de la mañana, cuya hora se anunciará al toque de la campana del Mercado, y estarán siempre en sitios separados a los destinados a las caseras, para que no puedan hacer sus compras fuera de la hora señalada, evitando con esto que el público compre a más subido precio el comestible.

Del mismo modo, los espacios ocupados por las recarderas estaban organizados de tal manera que quienes no tuvieran «cajones dentro del edificio o en las marquesinas», debían colocarse «en el banco corrido y numerado de la marquesina interior». Lógicamente, las tarifas a abonar eran diferentes según despacharan sus productos en uno $\mathrm{u}$ otro emplazamiento ${ }^{16}$.

\section{PERFIL SOCIOLÓGICO}

Aunque lo expuesto hasta el momento nos ha aportado ya una idea básica sobre la condición social de las mujeres ocupadas en este cometido, en este punto vamos a reflexionar un poco más sobre este aspecto. En primer lugar, un rasgo común de las mujeres dedicadas a este oficio era su falta de recursos y la precariedad a la que estaban sometidas. Aunque son varios los indicios que apuntan en ese sentido, las controversias que solían mantener con la Administración constituyen uno de los testimonios más claros de la escasez de medios a su alcance.

El impago de las tasas establecidas para la venta callejera o la no satisfacción de las sanciones económicas que les eran impuestas podían acarrear verdaderos problemas a las recarderas, pero estas no siempre disponían de efectivo para liquidar sus deudas. Entre las diversas situaciones provocadas por esta cuestión, destaca lo ocurrido a Josepha Garralda, pues le fueron embargadas sus ropas como pago de los dos ducados debidos «por el banco de recardería que goza por el plazo del año de mil setecientos setenta y cinco». La recardera solicitó le fueran devueltas la saya, el delantal y la capa decomisadas en razón a su extrema pobreza, pero, lejos de ser considerada su petición, también le fue retirada la "gracia de recardera».

Las demandas de este tipo abundaban y, si bien en ellas existiría una dosis de malicia y picardía, no hay duda de que se partía de circunstancias económicas poco favorables. Otro caso parecido lo protagonizó Manuela de Osacáin, recardera de la calle de la Tejería, pues debido a su condición de viuda, así como a las calamidades y enfermedades

16 Ayuntamiento de San Sebastián (1890). Reglas a que deberán sujetarse las personas que se dedican a la venta de artículos comestibles en los mercados de la ciudad de San Sebastián. San Sebastián: Imprenta de los Hijos de I. R. Baroja. 
padecidas, manifestó que no disponía de fondos para abonar el pago de la licencia pertinente. Para prevenir la posibilidad de embargo, se adelantaba exponiendo que le había "sido forzoso vender sus pocos trastos y recardería malbaratados». En términos similares se expresaba Paula de Xabarri cuando argumentaba que por sus repetidas enfermedades no había vendido nada, por lo que pedía se le perdonaran las cantidades debidas ${ }^{17}$.

En cualquier caso, las posibles suspicacias implícitas en estas declaraciones no son sino una muestra más del nivel de pobreza del sector de la población empleado en estas labores. Como ha quedado expuesto anteriormente, la participación laboral de la mujer al margen del ámbito doméstico no estaba bien vista según el criterio imperante en la sociedad tradicional. Por esta misma razón, el trabajo fuera del hogar denotaba una situación de vulnerabilidad fa-

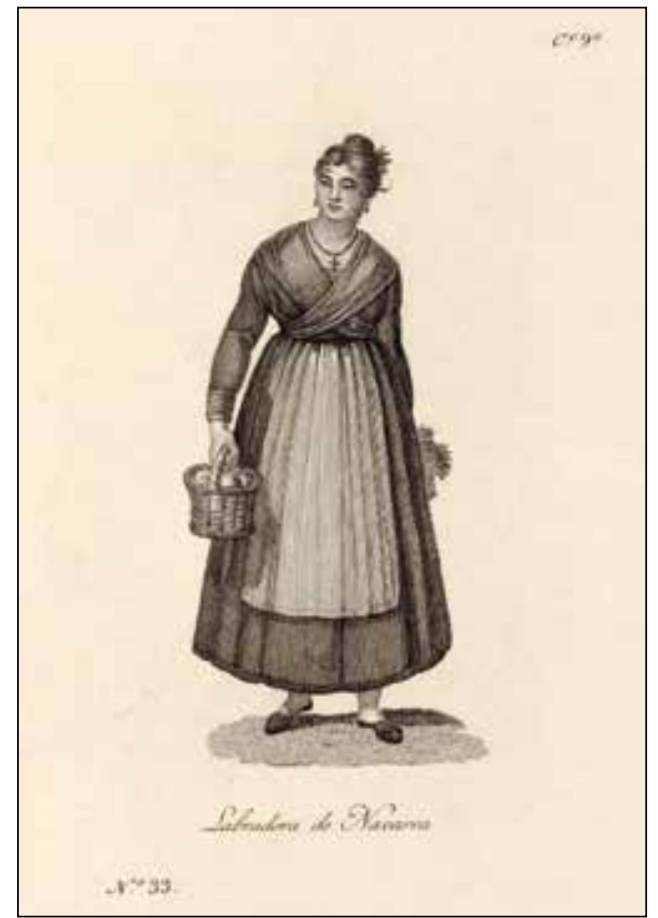

Figura 4. Labradora de Navarra con productos de la tierra. Grabado de Juan Carrafa, 1825. Biblioteca Digital Hispánica (BNE). miliar, puesto que, de no estar en una posición de verdadera necesidad, era una práctica que se tendía a evitar. En definitiva, muchas de las mujeres que optaban por este tipo de trabajo externo eran viudas sin otra opción de obtener recursos, o casadas obligadas en gran medida por las circunstancias familiares.

Los registros de recarderas realizados por la Administración a fin de cobrar las tasas por la licencia para ejercer el oficio evidencian esta procedencia social. Aunque cada autorización de recardería se asignaba a nombre de la mujer solicitante, a continuación, prácticamente en la totalidad de los apuntes se consignaba si esta era viuda o estaba casada. En este segundo caso, la identificación del marido aparecía siempre junto al nombre de la solicitante, lo que es una muestra más del papel preponderante de la figura masculina en los cánones morales e ideológicos del pasado ${ }^{18}$. En última instancia, esta singular forma de completar los censos respondía al requisito exigido por el Regimiento de que las solicitantes de licencias de recardería contasen previamente con el permiso marital (Díez de Ure, Fernández, Pinillos \& Roda, 1998, p. 164).

17 AMP, Empleados, leg. 13, carp. 10: Recarderas (1730-1772).

18 AMP, Empleados, leg. 16, carp. 1: Recarderas (1815-1838); «roldes». 
La extrema competitividad existente entre las distintas recarderas es otro elemento revelador de lo precario de la situación de estas mujeres trabajadoras. El hacerse con el género de más calidad y al menor precio requería de unas artes especiales, pero también era preciso adelantarse al resto de compañeras de oficio. El llegar en primer lugar a determinado mercado o feria suponía una ventaja considerable a la hora de adquirir o vender mercaderías en mejores condiciones, por lo que, a menudo, estas mujeres realizaban sus desplazamientos cuando todavía no había amanecido (Campos \& Rodríguez, 2000, p. 452). Así pues, la astucia necesaria para actuar de esta manera era otra de las características definitorias de las recarderas.

Sin embargo, no era el beneficio económico lo único que estaba en juego, el prestigio mismo de la recardera era otro de los factores que incitaban a estas trabajadoras a ser lo más competentes posible. La narración de Pablo Rodríguez (1933, pp. 191-196) sobre una recardera de la Solana refleja a la perfección esta disposición. Sucesora en el oficio de la tradición familiar, lo más importante para la Ricarda, junto con la ganancia monetaria por cumplir con el recado encomendado, era mantener su reputación y buen hacer como recardera, pues en el fondo esto también suponía una garantía de cara a futuros encargos y clientes.

La constancia en el trabajo era importante para conocer y tener un contacto directo tanto con los proveedores como con los consumidores. Esta era una ocupación en la que había que ser tenaz y no cejar en el empeño diario, pues solo de esta manera se podía estar al tanto de las vicisitudes del mercado y lograr la confianza de la clientela. Muchas recarderas se iniciaron de muy jóvenes en el oficio y lo desempeñaron a lo largo de toda su existencia. La prensa estatal llegó a hacerse eco de alguno de estos casos. El diario La Iberia, en su edición vespertina del 22 de agosto de 1893, informaba del fallecimiento «en Irún de una mujer de setenta y tres años llamada Josefa Ignacia, que durante sesenta años se ha dedicado al oficio de recardera entre aquella localidad y el Valle de Oyarzun».

El atractivo de la noticia radicaba en el trabajo desempeñado por la recardera guipuzcoana, pues se recalcaba que «todos los viajes los ha realizado a pie, y hasta hace muy pocos años cargada de una cesta sobre la cabeza». Allegados de la finada aseguraban que, excepto los días que permaneció enferma antes de morir, durante sesenta años no había faltado ni una sola jornada a su tarea. Los cálculos realizados por el corresponsal concluían que la distancia recorrida en vida por la recardera era de 261000 kilómetros, lo que implicaba que la señora había completado unas seis veces y media el ecuador terrestre. Dejando a un lado lo anecdótico del asunto, lo cierto es que la reseña evidencia de una forma amable la dureza y perseverancia necesaria en el desempeño de la profesión.

A las cualidades mencionadas, hay que añadirle también una mínima dosis de desconfianza, pues el hecho de estar a disposición de los distintos encargos realizados por sus convecinos podía acabar acarreando algún que otro disgusto a la recardera según fuera la encomienda recibida. Así le sucedió a Damiana Pérez, recardera de Rada que en noviembre de 1893 se vio envuelta en el proceso seguido por el triple crimen ocurrido 
en la localidad un año antes. El hecho de que uno de los acusados hubiera solicitado a Pérez la adquisición de pistones para trabuco en una casa de Sangüesa hizo que esta tuviera que declarar en el juicio sobre el tipo de recados que realizaba ${ }^{19}$. La causa no deparó mayores consecuencias para la recardera, pero, a buen seguro, en las sucesivas ocasiones habría puesto una mayor atención en la naturaleza de sus servicios.

Otra de las peculiaridades del oficio y de la personalidad de las recarderas venía dada por el hecho de ser una actividad ejercida a pie de calle, en un ambiente por el que transitaba y se reunía una alta cantidad de público. La concurrencia a los mercados y ferias buscaba resolver las necesidades de abastecimiento de la población, pero no se puede obviar la función social cumplida por estos espacios. Las relaciones establecidas entre los diferentes agentes que interactuaban en el escenario de la plaza se centraban en multitud de aspectos, si bien uno de los más destacados era el atractivo que la vida íntima de las personas despertaba en este tipo de foros. A este respecto, era muy diferente el grado de participación en esta dinámica de las asistentes ocasionales a la plaza del protagonizado por las recarderas, pues estas pasaban en el lugar la mayor parte de la jornada. Esto las colocaba en una situación central y privilegiada mediante la cual acceder a las intrigas y murmuraciones sobre el proceder de una parte muy importante del vecindario.

Sin embargo, no todo eran complacencias en esta posición, ya que, en ocasiones, el saber más de la cuenta también provocaba sus disgustos. Nuevamente encontramos a dos recarderas en el juzgado, pero esta vez por causas no relacionadas directamente con su labor. El juicio por el crimen pasional producido en Donostia a comienzos de 1883, en el que se vio envuelta una compañera, llevó al estrado a María Ventura Asteasu, de veinticinco años, soltera y recardera, y a María Esteban Azcue, de treinta años, casada y recardera. Las testigos, buenas conocedoras de las habladurías locales, manifestaron que era «cierto el rumor del próximo matrimonio de Zubeldía, y que la Ignacia tenía necesidad de una navaja para la venta de algunos artículos [...]» ${ }^{20}$.

\section{RECARDERAS PAMPLONESAS}

Las necesidades de una ciudad como Pamplona en materia de consumo implicaban la presencia continuada de recarderas dedicadas a aprovisionar a la población de frutas, verduras, huevos y otros alimentos básicos. La ubicación de esta actividad en el centro de la ciudad ha dejado numerosos testimonios de los cuales nos hemos valido a la hora de acercarnos a la figura de estas trabajadoras. Por este motivo nos parece oportuno dedicarle un pequeño apartado al modo particular de organización desarrollado por las recarderas pamplonesas.

19 El Liberal Navarro, 16/11/1892, 17/11/1892 y 18/11/1892.

20 La Iberia, 17/4/1883. 
Antes de nada, es preciso aclarar que en Pamplona operaban dos categorías distintas de recarderas. Por un lado, estaban aquellas vendedoras que disponían de un banco de recardería y despachaban en un punto fijo los productos para los cuales habían obtenido autorización previa. La otra variante también precisaba de licencia para ser ejercida, pero era más difícil de controlar, ya que se trataba de vendedoras que deambulaban por la ciudad ofreciendo a los transeúntes sus mercaderías. No obstante, dentro de que ambas modalidades eran actividades muy básicas, las recarderas que disfrutaban de un puesto estable contaban con mayores posibilidades de obtener beneficios de su modesto negocio.

La aspiración de las vendedoras ambulantes era poder llegar a instalarse en un tenderete fijo, pues el trabajo era menos penoso y, al estar emplazadas siempre en un mismo punto, la clientela habitual podía localizarlas sin ningún problema, lo que creaba unas mayores expectativas de venta. Aun así, lograr una de estas licencias no resultaba fácil. Los regidores municipales no tenían costumbre de hacer excepciones en la aplicación de la norma y en el cobro de las tasas. Ni siquiera la solicitud cursada en mayo de 1815 por Josefa Carreras les hizo cambiar su criterio. Esta pamplonesa, de setenta y siete años, expuso a la autoridad local que no podía «soportar el peso de una cesta de marchantería por su avanzada edad para ir vendiendo por las calles», por lo que solicitaba permiso "para poner dicha cesta al lado de María Cebada, marchanta que está enfrente del repeso, pagando lo que fuese de costumbre». La recardera confiaba en que se le concediera «la gracia de poder estar vendiendo en dicho puesto», pero la respuesta del Regimiento fue rotundamente contraria ${ }^{21}$.

Las vendedoras que habían obtenido "gracia» para contar con un banco de recardería estaban distribuidas en diferentes calles y zonas de la ciudad. Teniendo en cuenta que hasta finales del siglo XIX no comienza a gestarse el Primer Ensanche o Ensanche Viejo, la superficie urbana de Pamplona quedaba reducida a las dimensiones del Casco Antiguo. Si se repara en las concesiones de licencias otorgadas en las primeras décadas de esa centuria, comprobaremos que su disposición espacial abarcaba en esencia la totalidad del callejero pamplonés. Los censos de recarderas realizados durante esos años verifican su presencia al menos en las siguientes calles y espacios: Mayor, San Lorenzo, Pellejerías, Carpinterías, Descalzos, San Francisco, San Antón, San Nicolás, San Gregorio, Rúa Chica, San Agustín, la Merced, Calderería y Tejería.

No obstante, el emplazamiento más estimado para practicar el oficio era el amplio espacio que se abría frente a la casa consistorial. El completo e inestimable estudio sobre el callejero pamplonés realizado por José Joaquín Arazuri recompone la evolución de la plaza desde el periodo medieval. La identificación del lugar con la venta y distribución de alimentos ha sido una constante en el tiempo, estando atestiguada la instalación de vendedoras de distintos géneros prácticamente a lo largo de toda su existencia. Con anterioridad incluso a la unión de los burgos en los que estaba dividida la superficie de Pamplona se daba ya cierta actividad comercial junto a la torre de la Galea. Una vez se fusionan los tres núcleos de población y la zona adquiere una clara posición de centralidad es cuando 
empieza a consolidarse el mercado de alimentos en los aledaños de la actual casa consistorial. Alguno de los nombres dados al lugar en el pasado confirma esta presencia del comercio alimentario. Por ejemplo, después de que el mercado de carnes fuera trasladado a la trasera de la sede municipal y durante un corto espacio de tiempo, la parte delantera fue conocida como calle de las Bercerías o de los Berceros, en referencia a la venta de berzas y verduras practicada en ese punto (Arazuri, 1979, p. 232).

En todo caso, tras ser identificada durante unos años como plaza del Regimiento y plaza del Chapitel, las denominaciones más perdurables y las que una mayor relación guardan con la función de mercado practicada por las vendedoras son las de plaza de la Fruta o de Arriba y plaza de Abajo. El Diccionario Geográfico-Histórico de España de la Real Academia de la Historia, editado en 1802 (p. 232), destaca que, a pesar de las cortas dimensiones de la plaza de la Fruta (un rectángulo de 80 varas de longitud y 26 de anchura), «se celebran en ella todos los mercados y la venta de carne, pescado, frutas y demás comestibles».

Por su parte, el Diccionario Geográfico-Estadístico-Histórico de Pascual Madoz, publicado a mediados del siglo XIX, es un poco más preciso e informa que «la plaza de la Fruta sirve, como su propio nombre indica, para la venta de frutas verdes y secas». Insiste asimismo en la cuestión de la falta de espacio, pero reconoce que «hay bastante comodidad, merced al excelente arreglo de los puestos y al orden que se manda observar». Respecto a la zona posterior de la casa consistorial, expone que la plaza de Abajo, destinada a la venta de carnes, pescado y todo género de hortalizas, tampoco es muy espaciosa, pero a la vez recalca su admirable distribución, pues «no se echa de menos una extensión mayor, ni medida ninguna para el aseo y comodidad de aquel lugar».

Las fuentes mencionadas nos aportan una información muy elemental y superficial sobre los espacios físicos donde se ubicaban estos mercados, por lo que, si queremos profundizar en cómo se organizaba internamente la actividad comercial desarrollada en ambas plazas, es preciso reparar en la documentación municipal. Las providencias adoptadas en la casa del Regimiento, mediante acuerdo verbal del 10 de septiembre de 1824 , son bastante esclarecedoras a ese respecto, ya que determinan tanto las condiciones de venta como la distribución de géneros en los dos emplazamientos.

Plaza de Arriba:

No se permitirá vender vino, sino fruta verde, seca, quesos, leche, mantequillas, aves y huevos. Las revendedoras de estos dos últimos artículos no podrán vender sino en la plaza de Santo Domingo. Las vendedoras de fruta forasteras se colocarán desde la loseta para arriba y también las de las huertas de Pamplona. Las vendedoras de fruta seca o recarderas, y las revendedoras de frutas, desde la loseta para abajo hacia la Casa de Ayuntamiento, pagando los sitios que ocupen y obteniendo, las que no tengan gracia de la Ciudad, permiso del señor semanero.

Plaza de Abajo:

No se permitirá vender sino verduras, melones, pimentones, tomates en el patio descubierto. Las hortelanas, laneras, marchantas y zapateras quedarán en sus sitios actuales en el cubierto. Las vendedoras forasteras de verduras, melones, pimentones, 
tomates, se colocarán en el patio descubierto de la calle que atraviesa la plaza desde las botigas del pan a las tablas del carnero. Las revendedoras del pueblo de verduras y demás, formarán calles a espaldas de las forasteras y, a izquierda y derecha, en los costados de las mismas a los extremos. Las vendedoras de lino, salvado, vasija, irán a vender sus efectos a la plazuela de Santo Domingo.

Las relaciones sociales establecidas, el regateo entre vendedoras y clientas, las voces elevadas anunciando las virtudes del producto... Evidentemente, el ambiente surgido en ese escenario constituye un aspecto importante a considerar para tener una visión más completa de la actividad desplegada en el entorno del mercado. Al menos dos observadores externos dejaron escritas sus impresiones sobre la atmósfera que se respiraba alrededor de los tenderetes de la plaza de la Fruta, si bien es cierto que sus sensaciones no se correspondían. Cuando Víctor Hugo se acercó a Pamplona en 1843, una de sus salidas fue precisamente a esta plaza, donde percibió un panorama bullicioso conformado por puestos al aire libre, llenos de loterías (rifas) y juegos de pasabolas, charlatanes llenos de palabras risueñas, transeúntes que se empujan, compradores presurosos y un torbellino de gritos, risas, injurias y canciones.

Radicalmente opuesto es el efecto que la misma visita causó en Juan Mañé y Flaquer unas décadas después. El catalán recomendaba a cuantos llegasen a Pamplona que no dejaran de ver este hermoso mercado: ni un grito, ni una disputa, ni un altercado que llegue a llamar la atención, los vendedores de ambos sexos enseñando silenciosamente sus mercancías, contestando en pocas palabras y en voz natural (Iribarren, 1985, pp. 150, 211). Seguramente, lo más adecuado sea no tomar al pie de la letra ninguna de las descripciones, sino optar por una vía intermedia y decantarnos por una mezcla de las dos, pues ambos turistas, a su manera, reflejarían una parte de la realidad.

Las denominaciones de plaza de la Fruta o de Arriba y plaza de Abajo estuvieron vigentes desde el siglo XVII hasta 1864, que es cuando se consideró que los tenderetes de fruta y verduras afeaban la delantera de un edificio tan honorable como la casa consistorial. Los puestos de venta fueron trasladados al antiguo edificio que antes ocupaba el pósito municipal, lugar donde se ubicó el nuevo centro de operaciones de la mayor parte de las recarderas pamplonesas. Como hemos expuesto anteriormente, el quehacer de estas trabajadoras se mantuvo vigente hasta bien entrado el siglo pasado. Uno de los «dialogando"" de Arako ${ }^{22}$, escrito en 1914, recreaba varias de las situaciones vividas en el mercado pamplonés, como la rivalidad establecida entre las recarderas pamplonesas y «esas otras que vienen de los pueblos y que suelen comprar de paso que vienen», o el tira y afloja con la clientela a la hora de fijar el precio de la docena de huevos.

Sin embargo, aunque una vez finalizada la Guerra Civil todavía siguen apareciendo referencias a mujeres dedicadas a este cometido, los cambios que, de forma vertiginosa, se sucedieron en todos los órdenes implicaron la desaparición definitiva del oficio. En las 
ciudades y cabeceras de comarca surgieron nuevas alternativas para el consumo, y en las pequeñas localidades no hacía falta ya confiar a nadie un encargo o recado concreto porque la generalización del automóvil acrecentó notablemente los desplazamientos. El grueso de la clase trabajadora se empleó principalmente en la industria emergente, dinámica a la cual, de forma lenta pero progresiva, comenzó a incorporarse también la mujer.

\section{REFLEXIÓN FINAL}

En gran medida, gracias a las monografías y aportaciones realizadas desde el campo de la etnografía sobre los modos de vida, costumbres y actividades desarrolladas por las clases populares somos conscientes de la influencia de estas en la articulación de las sociedades pretéritas y actuales. Igualmente, investigadores partidarios de la llamada historia social han contribuido de manera notable en poner de manifiesto la participación y condi-

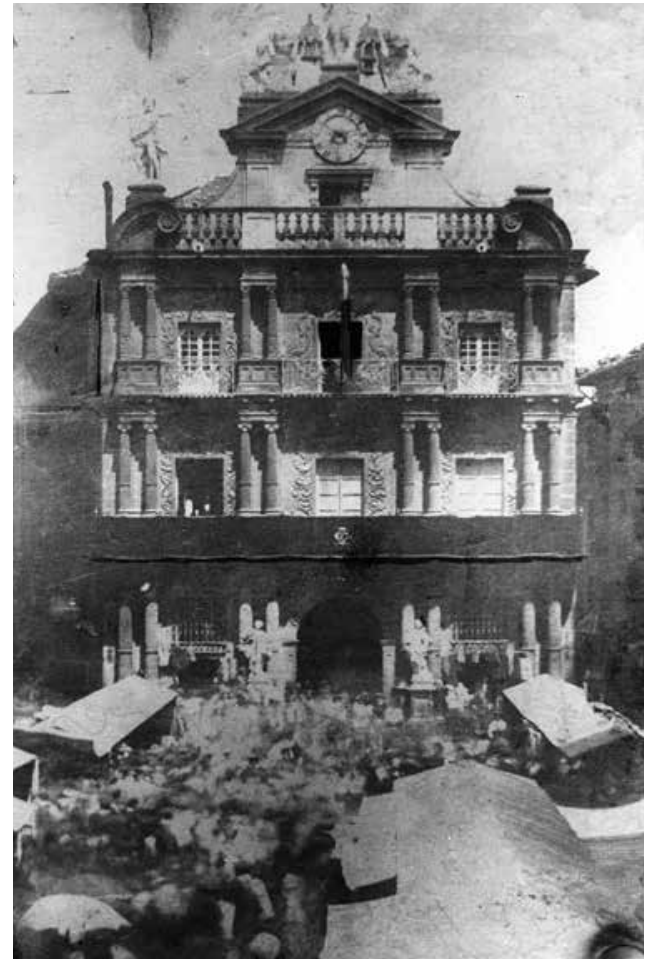

Figura 5. Vista de la plaza de la Fruta con los tenderetes de venta. Autor desconocido. Fotografía anterior al año 1864. Arazuri (1979, p. 229). AMP, Colección Arazuri. cionamiento de la ciudadanía de a pie en el devenir histórico de la humanidad. No obstante, todavía persiste cierta lectura del pasado que atribuye en exclusiva a los ámbitos del poder (económico, político, religioso, cultural...) la capacidad de configurar las dinámicas determinantes para la comunidad.

La postergación de la masa humilde trabajadora derivada de este tipo de planteamientos es doble en el caso de la mitad femenina de la población, pues la tradicional concepción androcéntrica de la organización social ha tendido a ignorar la acción de las mujeres. El no reconocimiento de estas funciones ha implicado un silenciamiento de su protagonismo en las interacciones que posibilitan el desarrollo y mantenimiento de los colectivos humanos. Sin embargo, conforme hemos expuesto en las páginas precedentes, misiones tan relevantes como la distribución final de los productos imprescindibles para subsistir han sido históricamente responsabilidad de grupos profesionales integrados mayoritariamente por mujeres. De acuerdo con el criterio de Mary Nash, investigadora especializada en el estudio de la historia de las mujeres, nombrar e incluir en el relato histórico la labor emprendida por estos colectivos resulta decisivo para dar presencia a una existencia negada (Blasco, 2019, p. 100).

El fenómeno de las mujeres dedicadas al comercio al por menor de productos alimenticios ha sido abordado con antelación por historiadoras de otras latitudes. Una de las 
propuestas más interesantes al respecto es la realizada en su día por Merry E. Wiesner (1990). El trabajo de esta autora sobre las buhoneras de Núremberg cuestiona si estas mujeres eran solo insignificantes vendedoras o hasta qué punto su tarea resultaba clave para el comercio y los servicios de esta ciudad alemana. En nuestro caso, la carencia de una aproximación a la intensa y temporalmente dilatada experiencia propia fue una de las causas que nos movió a acometer esta investigación. Así pues, el propósito del presente trabajo ha sido precisamente el de acercarnos a la realidad de las recarderas locales a lo largo del tiempo con objeto de conocer diferentes aspectos de la profesión para, de esta manera, estar en condiciones de poner en valor su quehacer.

Por otro lado, las inesperadas circunstancias que a nivel global han sobrevenido recientemente han venido a reforzar este enfoque. El primer borrador de este estudio fue realizado a comienzos de 2020, cuando aún no éramos mínimamente conscientes de la verdadera magnitud de los penosos efectos que iba a acarrearnos una pandemia mundial como la que estaba por llegar. De hecho, unos meses más tarde, en el momento de revisar y concluir este artículo sobre las antiguas recarderas, no está del todo claro cuál va a ser la evolución ni el desenlace final de la situación. En cualquier caso, son muchas y variadas las ideas y conclusiones que lo sucedido ha suscitado respecto a las formas de organizar la existencia humana como al modo en que se ha afrontado la enfermedad. No es nuestra intención entrar a valorar tales análisis, pero nos parece oportuno considerar la revalorización producida acerca de la proyección social de determinadas actividades profesionales.

Sin duda alguna, la labor ejercida por el diferente personal sanitario ha resultado fundamental en estos tiempos, lo que ha servido para recordar la importancia de contar con un sistema público de calidad al alcance de todas las personas que salvaguarde la salud de la comunidad. Así mismo, en este escenario también ha sobresalido el cometido esencial de otras profesiones -algunas de ellas no del todo reconocidas habitualmente-, como la de quienes han posibilitado el suministro de alimentos y otros bienes de consumo de primera necesidad. Curiosamente, es el perfil femenino el que predomina en ambas actividades, tanto en el sector de la atención sanitaria como en el relacionado con el abastecimiento de productos alimenticios elementales. En este sentido, las dependientas del pequeño comercio y las empleadas de grandes superficies, como cajeras y reponedoras, han desempeñado una tarea pareja a la que antaño realizaban las recarderas. Esperemos que la evidencia de lo vivido permanezca y no olvidemos el carácter primordial para la sociedad de estas y otras ocupaciones de naturaleza similar.

\section{ANEXOS}

\subsection{Registros de recarderas}

A lo largo del tiempo, todas las instituciones públicas han recaudado diferentes tributos que les permitieran disponer de efectivo para poder financiar su actividad administrativa. En Pamplona, el gravamen aplicado al comercio de los productos de consumo y el cobro por la licencia concedida a las recarderas para ejercer su oficio suponían dos de 
los ingresos periódicos que contribuían a incrementar la hacienda municipal. La confección de censos con el registro de estas vendedoras era fundamental para el cobro de estos impuestos. Seguidamente reproducimos los listados correspondientes a diferentes momentos de comienzos del siglo XIX ${ }^{23}$. Estos documentos son una muestra importante de la representatividad alcanzada por el oficio de recardera en una población como Pamplona durante aquellos años.

\subsection{1. «Rolde de recarderas del plazo de Navidad de 1800»}

Rol de las personas que mediante gracia de la Ciudad tienen banco de recardería y venden fruta, castañas y otros géneros, en las calles y plazas de ella, con expresión de lo que deben pagar por dichas gracias, a los propios y rentas de la misma, que es un ducado cada una de las recarderas de las calles, dos ducados las que solo venden fruta y huevos en las plazas de Arriba y de Abajo y botigas a su inmediación; y quatro ducados las que a más de fruta venden también castañas en dichas plazas; cuya cobranza corre a cargo del tesorero de dichos propios y rentas; y la de este rolde es respectiva al año que se cumplió en Navidad de 1800.

\begin{tabular}{|c|l|c|c|}
\hline $\mathbf{N}^{\mathbf{o}}$ & \multicolumn{1}{|c|}{ Calle Mayor } & Reales & Maravedís \\
\hline 1 & Saturnina Guereta, mujer de Machín Irurzun, alguacil. & 11 & \\
\hline 2 & Lázaro Zizur, sastre. & 11 & \\
\hline $\mathbf{N}^{\mathbf{o}}$ & \multicolumn{1}{|c|}{ San Lorenzo, Pellejerías. Carpinterías y Descalzos } & Reales & Maravedís \\
\hline 3 & Sebastiana Górriz, viuda de Marcos Ibáñez; Pellejería. & 11 & \\
\hline 4 & Manuela Roncal. & 11 & \\
\hline 5 & Rafaela Sarasíbar, mujer de Gregorio Armendáriz; Pellejería. & 11 & \\
\hline 6 & Juana Villanueva, mujer de Fausto Monteagudo; San Lorenzo. & 11 & \\
\hline 7 & Manuela Ochoa, viuda de Manuel de Soto; dicha calle. & 11 & \\
\hline 8 & Francisca Sancho, mujer de Pedro Soteras; Descalzos. & 11 & \\
\hline $\mathbf{N}^{\mathbf{o}}$ & San Francisco, San Antón, San Nicolás, San Gregorio y & Reales & Maravedís \\
\hline 9 & Réa Chica & & \\
\hline 10 & Ignacia Noáin, viuda de Félix Huarte; calle Comedias. & 11 & \\
\hline 11 & Antonio Elorz; calle San Miguel. & 11 & \\
\hline 12 & Manuela Echalecu; calle de San Gregorio. & 11 & \\
\hline 13 & María Arlegui; viuda de dicha calle. & 11 & \\
\hline 14 & Micaela Galar, mujer de Josef Marín. & 11 & \\
\hline 15 & Gerónima Elizondo, mujer de Francisco Caminos. & 11 & \\
\hline $\mathbf{N}^{\mathbf{o}}$ & San Agustín, la Merced, Calderería y Tejería & Reales & Maravedís \\
\hline 16 & María Bernarda Egozcozabal; Calderería. & 11 & \\
\hline 17 & María Guerendiáin; Tejería. & 11 & \\
\hline & & & \\
\hline
\end{tabular}

23 AMP, Empleados, leg. 16, carpeta 1: Recarderas (1815-1838); «roldes». 


\begin{tabular}{|c|l|c|c|}
\hline 18 & María Josefa Monreal; dicha calle. & 11 & \\
\hline 19 & Martina de Goñi, dicha calle. & 11 & \\
\hline 20 & $\begin{array}{l}\text { Josefa Goicochea, mujer de Andrés Otaño. Debe por lo corrido desde } \\
\text { Navidad de 99 hasta Navidad de 1800, en que hizo dejación de la gracia. }\end{array}$ & 11 & 9 \\
\hline 21 & $\begin{array}{l}\text { Francisco Asensio. Debe por lo corrido desde 26 de marzo de 1800 en que se } \\
\text { le hizo gracia de banco de recardería para su casa, mediante haber dejado el } \\
\text { que tenía en la plaza hasta Navidad del mismo año. }\end{array}$ & 8 & 9 \\
\hline 22 & $\begin{array}{l}\text { Saturnina de Lana, mujer de Nicolás de Astráin. Debe por lo corrido desde } \\
\text { 26 de marzo de 1800 en que se le hizo gracia hasta Navidad. }\end{array}$ & $\begin{array}{l}\text { Juana Martina Aranguren, viuda; calle de la Calderería. Debe por lo corrido } \\
\text { desde 15 de noviembre de 1800 en que se le hizo gracia hasta Navidad del } \\
\text { mismo año. }\end{array}$ & 1 \\
\hline
\end{tabular}

\begin{tabular}{|l|l|l|l}
\hline $\mathbf{N}^{\mathbf{0}}$ & Plazas de Arriba y de Abajo & Reales & Maravedís
\end{tabular}

\begin{tabular}{|c|c|c|c|}
\hline 24 & María Eguaras; plaza de Arriba. Gracia de banco y castañas. & 44 & \\
\hline 25 & Francisco Asensio; dicha plaza. Gracia de venta de castañas. & 22 & \\
\hline 26 & $\begin{array}{l}\text { El mismo. Debe gracia de la recardería que tenía en dicha plaza y prorrata } \\
\text { corrida desde Navidad de } 99 \text { hasta } 26 \text { de marzo de } 1800 \text { en que hizo dejación } \\
\text { de ella. Gracia que se le concedió dicha recardería para su casa de la calle de } \\
\text { la Tejería a razón de dos ducados anuales. }\end{array}$ & 5 & 18 \\
\hline 27 & Teresa Fernández, viuda de Pablo Lorenzo; dicha plaza. Banco y castañas. & 44 & \\
\hline 28 & Francisca Rubio, mujer de Víctor Carnero; dicha plaza. Banco y castañas. & 44 & \\
\hline 29 & Francisca Larumbe, mujer de Vicente Zarragual; dicha plaza. Solo castañas. & 22 & \\
\hline 30 & Ramona Elcano, mujer de Antonio Acedo; dicha plaza. Solo castañas. & 22 & \\
\hline 31 & Fermín Urtasun; dicha plaza. Recardería. & 22 & \\
\hline 32 & Francisco Osés; por banco en dicha plaza. & 22 & \\
\hline 33 & María Teresa Marchueta; mujer de Francisco Pavón. Ídem. & 22 & \\
\hline 34 & Bárbara Oñate. Ídem. & 22 & \\
\hline 35 & Isidora Ganuza, hija de Ángela Recarte. Ídem. & 22 & \\
\hline 36 & Antonia Huarte, viuda de Miguel Martín de Cía. Ídem. & 22 & \\
\hline 37 & Agustina Andueza, mujer de Manuel Martínez. Ídem. & 22 & \\
\hline 38 & Manuela Múzquiz. Ídem. & 22 & \\
\hline 39 & Bernardo Gallarza y Fermina Aranguren, su mujer. Ídem. & 22 & \\
\hline 40 & Josefa Cemboráin. Ídem. & 22 & \\
\hline 41 & Benita Recalde, mujer de Joaquín Urrutia. Ídem. & 22 & \\
\hline 42 & Francisco Larbarreras y Manuela Abadía, su mujer. Solo castañas. & 22 & \\
\hline 43 & Josefa Iriarte. Recardera bajo el almudí. & 22 & \\
\hline 44 & $\begin{array}{l}\text { Lorenza Loitegui. Por el sitio que ocupa en la plaza de Arriba en la venta de } \\
\text { huevos y año cumplido en } 25 \text { de diciembre de } 1800 \text {. }\end{array}$ & 11 & \\
\hline & Total & 738 & 6 \\
\hline
\end{tabular}

Suma este rolde setecientos treinta y ocho reales y seis maravedís, salvo error. Con acuerdo de la ciudad de Pamplona, casa del Regimiento. Es copia del rolde original que para la cobranza se entregó al tesorero Felipe Andrés de Larrañeta.

\section{Pamplona, 17 de enero de 1801. \\ Firmado: Joaquín López.}




\subsection{2. «Rol de recarderas de la plaza de la Fruta - 1820»}

Recarderas que debe haber en la Plaza de la Fruta de la loseta del medio hacia la Casa de Ayuntamiento.

- Lado de la casa de Echechipia, contando de la Casa de Ayuntamiento:

1. ${ }^{a}$ Josefa Cía, mujer de Miguel Úriz.

2. ${ }^{a}$ Manuela de Abadía, mujer de Francisco Barrer.

3. alejandra Fernández, viuda (murió; entró en su lugar Francisca Recalde).

4. ${ }^{a}$ Ramona Elcano, viuda de Antonio Acedo.

5. ${ }^{a}$ Francisca Larumbe, mujer de Vicente Zarraz.

6. ${ }^{a}$ Antonia Recarte, mujer de Vicente Carnero.

7. María Pomés, viuda de Francisco Santa María (fue suspendida; entró Gregoria Zarragual).

8. ${ }^{a}$ Agustina Zarragual, mujer de Fermín Elía.

9. Isidora Ganuza, viuda.

- Lado de la casa de Larreta, contando de la Casa de Ayuntamiento:

1. ${ }^{a}$ Josefa Erro, mujer de Crispín Blanco.

2. ${ }^{a}$ Antonia Asensio, viuda (lo dejó; entró Manuela Esparza).

3. a Teresa González, soltera (fue suspendida y entró Bernarda Lizaso).

4. ${ }^{\text {a }}$ Josefa Ayerra, viuda.

5. Josefa Rentería, viuda (lo dejó, entró Rosa Fernández).

6. Juana Barrinaga (anteriormente, Francisca del Royo).

7. Javiera Aldabe (anteriormente, Micaela Ameztoy, viuda).

- Personas que en la plaza de la Loseta y plaza de arriba pueden vender fruta:

Por Manuela Ancil, huerta de Bergara, María Engracia Álvarez.

Por José Juan de Subiza, huerta de Larreta, Graciosa Azpíroz.

Por Joaquina Berascun, huerta de Barañáin, Simona Urdániz.

Por Javiera Sarbide, huerta de Burlada, María Teresa Yzu.

Por Antera Munárriz, huerta de Biguria, Francisca Barreneche.

Por Josefa García de Tafalla, María Jesús Ayala.

Por la huerta de Zuza, Estefanía Lizaso.

Por la huerta de García, Francisca Yturralde.

Por José Pascual, hortelano del conde en Tafalla, Francisca Matheo.

Por Miguel Pascual, hortelano del conde en Tafalla, Joaquina López.

Estefanía Luzuriaga, Martina Ardáiz, Bernarda Lizarza y María Azanza. Estas pueden vender las frutas que traen sus maridos.

Nadie más tiene gracia en la Plaza, hoy primero de enero de 1820.

Firmado: Luis Serafín López. 


\subsection{3. «Rol de recarderas de la plaza de la Fruta - 1826»}

Nota de la recarderas de fruta de la loseta para arriba. Tienen papel.

Arreglo de los puestos de las recarderas de fruta verde de la plaza de la Fruta de la loseta para arriba.

- Costado de la derecha de la Casa de Ayuntamiento:

2. ${ }^{\circ}$ Puesto de María Azanza, mujer de Francisco Guerrero.

3. ${ }^{\circ}$ Puesto: Francisca Cía.

4. ${ }^{\circ}$ Puesto: Celestina Domínguez.

5. ${ }^{\circ}$ Puesto: Francisca Istúriz, mujer de Francisco Orayen.

6. Puesto: Martina Ardáiz, mujer de Fermín Elizeche.

7. ${ }^{\circ}$ Puesto: Juana María Samaniego, por dos meses solamente.

8. ${ }^{\circ}$ Puesto: Manuela Esparza, mujer de Fermín Remón.

9. Puesto: María Lucas Urriza.

10. ${ }^{\circ}$ Puesto: Vicenta Lizasoáin.

- Costado de la izquierda de la Casa de Ayuntamiento:

1. ${ }^{\circ}$ Puesto: Severiana Ripalda y Josefa Berasáin.

2. ${ }^{\circ}$ Puesto: Joaquina Acedo.

3. ${ }^{\circ}$ Puesto: Josefa Eusa, mujer de José Azpíroz.

4. ${ }^{\circ}$ Puesto: Estefanía Luzuriaga, mujer de Pedro Gil.

5. Puesto: Mauricia Orcoyen.

6. Puesto: María Ibáñez.

7. Puesto: Micaela Larumbe.

8. Puesto: María Estefanía Beunza.

$9 .{ }^{\circ}$ Puesto: Juliana Urricelqui.

Estas diez y siete mujeres se colocaron en los puestos señalados, pero solamente mientras no haya forasteras que vendan la fruta, como suele suceder en la estación de la abundancia de ella, pues entonces deberán colocarse estas mujeres a la espalda de sus respectivos puestos, o mejor no salir a la plaza en aquel tiempo.

Deberán pagar cuatro maravedís diariamente por el puesto a la persona encargada. A todas se les proveerá de un papel en que se exprese que son recarderas. Cualquiera otra que haya de colocarse en la plaza deberá acudir a solicitar licencia y la asignación del puesto.

No se han de mezclar en vender otra cosa que fruta verde.

No han de poder cambiar de puesto, ni cederlo a otra persona.

Han de pagar del derecho de peso y expediente y alcabala de la fruta.

92 Cuadernos de Etnología y Etnografía de Navarra (CEEN), 94, 2020, 63-98

ISSN: 0590-1871 ISSN-e: 2530-5840 ISSN-L: 0590-1871 
Siempre se han de considerarse los forasteros con derechos preferente a colocarse en la plaza quando traen fruta donde les acomode, sin que puedan estorbárselo las recarderas.

\section{Pamplona, 18 de diciembre de 1826. \\ Firmado: Luis Serafín López.}

\subsection{Normativa reguladora}

Aunque el cometido de las recarderas era de naturaleza modesta, suscitaba efectos verdaderamente transcendentales en la vida diaria de la comunidad. Es por ello que las autoridades tendieron a regular su actividad decretando aspectos tan importantes como el establecimiento de los precios, los horarios en los cuales podían autoabastecerse estas revendedoras y su distribución espacial, entre otras cuestiones. Algunas de estas normas estaban incluidas en las ordenanzas generales de determinadas localidades, pero la actividad desplegada en Pamplona en este sector era de tal magnitud, que se acabó dictando un reglamento específico para las recarderas de la ciudad ${ }^{24}$.

«Hordenanzas de la plaça y chapitel de los recarderos y fruteros»

Primeramente, estauimos y ordenamos que en dicha Ciudad aia número de recarderos que vendan sardinas, pescado, arenques y queso y aceite y otras cossas saladas y que, en toda la Ciudad, destos no habrá salvo veinte y quatro, los quales serán repartidos por los regidores cómo y quánto han de ser, así en la plaça del chapitel, como fuera de ella, en los calliforques y cantones; que ningún otro pueda usar del dicho oficio salvo los que así por el Regimiento serán nombrados y del dicho Regimiento lo tendrán así, so pena de quince libras, repartideras, la mitad para el acusador y la otra mitad, para los ussos desta Ciudad.

2. Que aya doce fruteros que vendan fruta y no cosa de sal ni aceite y, siendo necesario, quantos el Regimiento quiera nombrar, pena de diez libras.

3. Que las fruteras y recarderas nombradas, antes que husen de sus oficios, agan juramento, en la casa del Regimiento en manos de los regidores, que justamente usarán sus oficios.

4. Que los recarderos y fruteros tengan licencia de los regidores para usar de sus cargos y den fianzas, pena de diez libras.

5. Que los recarderos y fruteros, que vendiesen aceites y sardinas, no vendan fruta y también el que vendiese pescado, sardinas, ni aceite, pena de tres libras.

24 AMP, Libro de las Hordenanzas de la ciudad y de diferentes oficios de esta de Pamplona, ff. 16-20 (reglamento datado por los investigadores Santiago Lasaosa (1979, p. 89) y Marcelino Núñez de Cepeda (1948, p. 234) en el siglo XVI). 
6. Que ningunas fruteras no vendan pescado, sardinas, ni aceite, pena de tres libras.

7. Que ningún vecino ni habitante desta Ciudad no salga afuera a comprar ni poner precio en ninguno provisión ni bastimento, pena advitraria.

8. Que ningún recardero, antes de entrar en la Ciudad ni después, no compren sardinas ni pescado asta que sea descargado y estimado, pena de diez libras.

9. Que, quando los recarderos allaren fraude en los cestos de sardinas y arenques, poniendo encima lo bueno y baxo el malo, lo que se debe hacer.

10. Que nadie compre en la Ciudad ni fuera para revender asta que pase las horas aquí limitadas, pena de seis libras.

11. Que nadie venda uvas frescas asta el día de nuestra Señora de Agosto, pena de perder las uvas y más tres libras.

12. Que no saquen a vender los recarderos ni fruteros, sardina ni pescada en bancos, más afuera de sus límites, pena de una libra.

13. Que nadie venda fruta ni en la plaza, ni en otra parte, fuera del número de los recarderos nombrados, pena de dos libras.

14. Que ningún pescado fresco de la mar descargue sino en la casa del Regimiento, pena de tres libras y lo mismo al que acogiere.

15. Que nadie venda pescado fresco de mar asta que sea estimado por el Regimiento, pena de seis libras.

16. Que ningún pescado fresco de mar se venda, sino en la red y pescadería de esta Ciudad, sin licencia del Regimiento, pena de diez libras.

17. Que ningún recardero, ni otra persona, sea osado de vender, dentro de la dicha Ciudad, ni en sus coseras, por menudo, ningún congrio, ni pescado leidal, arenques, sardinas, ni queso fresco ni asentado antes de ser estimado, como dicho es, y puesto precio por los regidores, so pena de seis libras.

Por traslado, Juan Ramírez de Urdánoz.

\subsection{Causas judiciales}

El cometido de las recarderas afectaba directamente a cuestiones tan serias como la manutención alimenticia y el bolsillo del conjunto de la sociedad sin distinción de clases. Así pues, no era extraño que, en numerosas ocasiones, las controversias surgidas en estas elementales relaciones comerciales acabaran solucionándose en los tribunales. La mayoría de las veces eran las propias recarderas las acusadas de actuar irregularmente, 
pero muchas de ellas también fueron víctimas de abusos e injusticias. Dado el bajo extracto social del que procedían estas mujeres, los efectos de ese tipo de fraudes podían resultar irreversibles para su modesta economía. En uno de estos casos se vio envuelta la mismísima casa del obispo, quien fue el destinatario de una misiva del Consejo Real de Navarra (1573). Dicho organismo tomó esta decisión motivado por la denuncia de una recardera que no había percibido el cobro de los productos despachados ${ }^{25}$.

Don Philippe, por la gracia de Dios, rey de Castilla, de Navarra, de Aragón, de León, de Toledo, de Sevilla, conde de Flandes: Prior, canónigo y cabildo de la Santa Yglessia Catedral de esta ciudad de Pamplona, el doctor Juan Cruzat, chantre della, que sois apostólico y cura de ánimas en este obispado, y quales quiera otras personas que en qualquier manera seréis interesados, que a la notificación de esta seréis nombrados, sabed que de parte de Juana de Ussi, recardera vecina de la dicha ciudad, ante nos, el regente y los del nuestro Consejo, se ha presentado la petición siguiente:

Juana de Ussi, recardera vecina de esta ciudad, dice que Juan de León, despensero que fue del obispo de Pamplona, defunto, llevó de la botiga de la suplicante, por muchos años, pescado, cereal, aceyte y todas las otras cosas que tenía en una botiga, para la despensa de la cassa del dicho obispo, y algunas aves; y también le prestaba dinero para comprar pescado fresco y velas de sebo y cera, y otras cosas; y al cabo de algunos días se mataban quentas y le pagaba lo que le alcanzaba. Y de esta manera sirvió a la cassa del obispo por tiempo de diez años, y más de resto de lo que le dio para dicha despensa de algunos días antes de que el dicho Juan de León, despensero, enfermó y le quedó debiendo diez y seis ducados y treynta tarjas, como parece por el memorial que asta el último viernes que estuvo enfermo le dio escripto y firmado de su mano, que es lo que presenta y de lo que le dio el sábado siguiente. A otra parte le quedó debiendo doze reales, como también parece en el memorial que presenta, y aunque luego que la suplicante tuvo noticia que el dicho Juan de León estaba enfermo, acudió al dicho despensero a que le pagase los dichos diez y siete ducados y treynta y quatro tarjas que montan las dichas dos partidas, el qual, reconociendo que era verdad que se le debían, hizo llamar ante sí al mayordomo Pero Gascón y al veedor Sarassa, los quales, en presencia de las otras personas de cassa del obispo, les manifestó que le debía la dicha cantidad y les encargó y rogó con todo encarecimiento que le pagasen la dicha cantidad y descargasen su conciencia, y aunque pidió aquella al obispo y a los dichos mayordomos y veedor, nunca se lo han querido pagar, de lo que recibe mucho daño en especial, que es la mayor parte de su caudal.

Suplica a Vuestra Magestad, a los albaceas y ejecutores testamentarios del último testamento del obispo, que luego paguen a la suplicante los dichos diez y siete ducados y treynta y quatro tarjas y media, y si fuere necesaria se reciba en forma. Es por ante que el quien eso decidió, el dicho despensero algunos días antes que muriese, manifestó deberle la dicha cantidad.

25 ARGN, Consejo Real de Navarra, Procesos judiciales, F017/068888. 
Leída la dicha petición, fue acordado que debíamos mandar esta nuestra carta para vos en la dicha razón por la qual os mandamos que, en tercero día de la notificación de esta nuestra carta, parezcáis en nuestro dicho Consejo por vosotros mesmos o por vuestro bastante procurador a tomar la dicha petición y dar causas por qué no se debe pagar la cantidad que el suplicante por la dicha petición inserta y pide, y estar a justicia con él sobre ella. Para lo qual y todos los otros autos que en esta razón se obreren, os citamos y emplazamos, y os señalamos nuestros estrados de las Audiencias Reales de nuestro Consejo, donde, si pareciéredeis, seréis oydos, y sino vuestra ausencia avida.

Por presencia se arán y notificarán los dichos autos, y por si vosotros mismos o por vuestro procurador se obiere echo duda se darán con el sello de nuestra ciudad.

En la ciudad de Pamplona, a diez de febrero de mil quinientos setenta y tres años.

Por mandato de su Magestad, el virrey regente y los de su Consejo.

Muy noble señor, don Diego Ramírez. Escribano de esta causa que contra los canónigos de la Madre Higlessia de dicha ciudad y los demás acreedores en los bienes del obispo de Pamplona.

\section{REFERENCIAS}

\subsection{Bibliografía}

Altadill y Torrenteras de Sancho, J. (1918-1921). Geografía General del País VascoNavarro, II. Barcelona: Establecimiento editorial de Alberto Martín.

Anaut Bravo, S. (2005). La dependencia obligada: la trampa de la protección en la vida cotidiana de las mujeres de Pamplona en el siglo XX. Pamplona: Ayuntamiento de Pamplona, Área de Servicios Sociales y Mujer.

Arazuri Díez, J. J. (1979). Pamplona, calles y barrios, I, A-D. Pamplona: José Joaquín Arazuri.

Arco y Garay, R. del. (1913). Ordenanzas inéditas dictadas por el Concejo de Huesca (1248 a 1456). Revista de Archivos, Bibliotecas y Museos, 11 y 12, 427, 452.

Baleztena, I. (1946). Relación de la Peste desta Ciudad de Pamplona del año 1599. Príncipe de Viana, 23, 377-394.

Barandiaran, J. M. \& Manterola, A. (dirs.). (1998). Euskalerriko atlas etnografikoa. Ritos del nacimiento al matrimonio. Bilbo: Laybaru Ikastegia.

Barandiaran, J. M. \& Manterola, A. (dirs.). (2011). Euskalerriko atlas etnografikoa. Casa y familia en vasconia. Bilbo: Laybaru Ikastegia.

Blasco, I. (2019). Entrevista a Mary Nash. Filanderas. Revista Interdisciplinar de Estudios Feministas, 4, 95-103. https://doi.org/10.26754/ojs_filanderas/fil.201944079

Bofarull y Sartorio, M. de, (1889). El Registro del Merino de Zaragoza, el caballero don Gil Tarín, 1291-1312, transcrito, anotado y acompañado de apuntes

96 Cuadernos de Etnología y Etnografía de Navarra (CEEN), 94, 2020, 63-98 ISSN: 0590-1871 ISSN-e: 2530-5840 ISSN-L: 0590-1871 
bibliográficos de la Familia de Tarín. Zaragoza: Imprenta del Hospicio Provincial.

Borao y Clemente, G. (1859). Diccionario de voces aragonesas precedido de una introducción filológico-histórica. Zaragoza: Imprenta y librería de D. Carlisto Ariño.

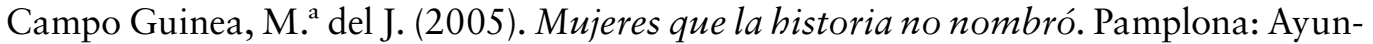
tamiento de Pamplona, Área de Servicios Sociales y Mujer.

Campos Santacana, M. K. \& Rodríguez Zamarreño, L. (2000). El papel de las mujeres donostiarras en los siglos XIX y XX. Vasconia. Cuadernos de historiageografía, 30, 447-455.

Coromines i Vigneaux, J. (1987). Breve diccionario etimológico de la lengua castellana. Madrid: Gredos.

Díez de Ure, A., Fernández, S., Pinillos, S. \& Roda, P. (1998). Ellas: las mujeres en la historia de Pamplona. Pamplona: Ayuntamiento de Pamplona.

Elzaurdia Zubieta, E. (1921). Voces vascas en los Fueros de Navarra. Boletín de la Comisión de Monumentos Históricos y Artísticos de Navarra, 45, 29-36.

Garralda Arizcun, J. F. (2011). Reformismo en los abastos del ayuntamiento de Pamplona. Siglo XVIII. Príncipe de Viana, 254, 251-275.

Garrido, E. (ed.), Folguera, P., Ortega, M. \& Segura, C. (1997). Historia de las mujeres en España. Madrid: Síntesis.

González Setién, P. (Centro Feminista de Estudios y Documentación) (1992). El trabajo de las mujeres a través de la historia. Madrid: Instituto de la Mujer.

Hernández Alonso, C. (cord.) (2001). Diccionario del castellano tradicional. Valladolid: Ámbito.

Ibáñez Basterrika, G. (2007). Aspectos de la etnografía e historia de Lumbier / Irunberriko etnografia eta historiaren zertzeladak. Inédito.

Iribarren, J. M. a (1985). Pamplona y los viajeros de otros siglos. Pamplona: Gobierno de Navarra.

Iribarren, J. M. a (1997). Vocabulario navarro. Pamplona: Diario de Navarra.

Jiménez de Aberasturi Corta, J. C. (1980). Aproximación a la historia de la comarca del Bidasoa. Príncipe de Viana, 160-161, 263-410.

Lasaosa Villanua, S. (1979). El «Regimiento» municipal de Pamplona en el siglo XVI. Pamplona: Diputación Foral de Navarra, Institución Príncipe de Viana.

Madoz, P. (1986). Diccionario geográfico-estadístico-histórico de España y sus posesiones de ultramar. Navarra (edición facsímil de la original de 1845-1850). Valladolid: Ámbito Ediciones.

Manterola, A. (1980). Etxea. En J. M. Barandiaran \& E. Ayerbe (dirs.), Euskaldunak. La etnia vasca. III (pp. 537-599). Lasarte-Oria: Etor-Ostoa.

Marín Royo, L. M. (2007). El habla en la Ribera de Navarra. Vocabulario y expresiones usadas en la merindad de Tudela. Zaragoza: Navarro \& Navarro Impresores.

Mugueta Moreno, I. (2017). Mercados locales e Industrias rurales en Navarra (12801430). En G. Navarro Espinach \& C. Villanueva Morte (coords.). Industrias y mercados rurales en los reinos hispánicos (siglos XIII-XV) (Monografías de la Sociedad Española de Estudios Medievales, 9) (pp. 145-174). Murcia: Sociedad Española de Estudios Medievales. 
Núñez de Cepeda Ortega, M. (1948). Los antiguos gremios y cofradías de Pamplona. Pamplona: Imprenta Diocesana.

Olivier Insausti, L. (1923). V Centenario de la publicación del Privilegio de la Unión por el rey D. Carlos III el Noble de Navarra. Pamplona: Artes Gráficas.

Pedrosa Bartolomé, J. M. (2000). Versiones extremeñas y panhispánicas del cuento de Tú pitarás. Revista de estudios extremeños, 56, 845-852.

Peralta, M. (1836). Ensayo de un diccionario aragonés-castellano. Zaragoza: Imprenta Real.

Real Academia de la Historia. (1802). Diccionario Geográfico-Histórico de España. Sección I. Comprehende el Reyno de Navarra, señorío de Vizcaya, y provincias de Álava y Guipúzcoa. Madrid: Imp. de la Viuda de D. Joaquín Ibarra.

Rodríguez González, P. (1933). Brochazos de la tierrica (cuadros de costumbres, tradiciones, narraciones, \&). Pamplona: Editorial Torrent Aramendía Hnos.

Roquero, M. ${ }^{a}$ R. (2019). Historia de las mujeres en Euskal Herria. Del viejo reino al antiguo régimen. Tafalla: Txalaparta.

Rucquoi, A. (1985). La mujer medieval. Barcelona: Información y revistas.

Segura Sierra, F. (2003). Ordenanzas municipales de Puente la Reina. Siglos XIV-XV. Principe de Viana, 228, 159-180.

Serrano Larráyoz, F. (1998). Banquetes de los príncipes de Viana a mediados del siglo XV. Príncipe de Viana, 215, 689-718.

Valle, T. del. (1996). Las mujeres en Euskal Herria. Ayer y hoy. San Sebastián: Orain.

Wiesner, M. E. (1990). ¿Buhoneras insignificantes o mercaderes esenciales? Las mujeres, el comercio y los servicios en Núremberg durante la edad moderna. En J. S. Amelang \& M. Nash (eds.), Historia y género: las mujeres en la Europa Moderna y Contemporánea (pp. 177-190). Valencia: Institució Alfons el Magnánim.

Zuaznávar Francia, J. M.‥ (1828). Ensayo histórico-crítico sobre la legislación de Navarra. San Sebastián: Imprenta de Ignacio Ramón Baroja.

\subsection{Hemeroteca}

Avalancha, La.

Diario de Navarra.

Eco de Navarra, El.

Iberia, La.

Liberal Navarro, El.

\subsection{Archivos y centros de documentación}

Archivo Municipal de Pamplona.

Archivo Real y General de Navarra.

Biblioteca Digital Hispánica.

Biblioteca Navarra Digital (BiNaDi).

Biblioteca Virtual de Prensa Histórica.

98 Cuadernos de Etnología y Etnografía de Navarra (CEEN), 94, 2020, 63-98

ISSN: 0590-1871 ISSN-e: 2530-5840 ISSN-L: 0590-1871 